\title{
Pathology of Environmental Advertising Management of Tehran Metropolis
}

\section{ART ICLE INFO}

\section{Article Type}

Original Research

\section{Authors}

Ilali S. H.* $M A$

Nami M. ${ }^{1} M A$,

Hoseini Amin S. N. ${ }^{2} P h D$

Boroujerdi Alavi M. ${ }^{3} \mathrm{PhD}$

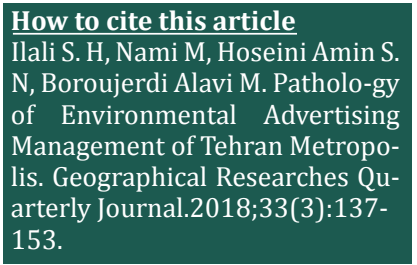

*Department of Communica-tion Sciences, Faculty of Communication Sciences, Allameh Tabataba'i University, Tehran, Iran

${ }^{1}$ Department of Governmental Management, Faculty of Management, Tehran University, Tehran, Iran

${ }^{2}$ Department of Sociology, Faculty of Humanities, Islamic Azad University Science and Research Branch, Tehran, Iran

${ }^{3}$ Department of Public Relations, Faculty of Communication Sciences, Allameh Tabataba'i University, Tehran, Iran

\section{*Correspondence}

Address: Unit 8, NO. 172, Maleklou Street, Heidarkhani Street, Resalat Highway, Tehran, Iran. Postal Code: 4119493168

Phone: -

Fax: -

Ha.ilali@yahoo.com

\section{Article History}

Received: May 30, 2018

Accepted: September 14, 2018

ePublished: December 09, 2018

\section{A B S T R A C T}

Introduction and Background Everything in urban space affects the beauty, lifestyle, culture, habits and behaviors of citizens and ultimately affects the city's identity. One of the main elements that plays in different ways in urban space is environmental advertising. Advertising is the most effective way of delivering cultural and business messages to audiences. All types of advertising in the open space, whether urban or suburban, are environmental advertisements. Such adver-tisements are displayed in different parts of the city in various ways such as wall paintings, billboards, urban furniture, portables, buses, subway and courtyard corners, street floor, optical and laser stands and stands everywhere in the city. It seems that urban spaces have been hit by environmental advertising. This has led the city to face more and more challenges.

Aims The purpose of this study was to identify the damage caused by environmental advertising management in Tehran.

Methodology The present study was conducted using qualitative method and thematic analysis. This analysis involves a continuous sweep between the data set and the set of coding and analyzing the data that was created. The theme is a duplicate and distinctive feature of the text which, according to the researcher, reflects a special understanding and experience in relation to research questions. Data were collected using a library and interview method. The sample consists of 34 experts, managers and experts related to environmental advertising; these interviews continued until the data collection was saturated. To select the interviewees, first the targeted-sampling and then the snowball sampling method was used and the MAXQDA software was utilised to analyze the interviews and plotting the content network model.

Conclusion Findings and research results in 8 main themes: management pathology, socio-cultural pathology, psychological pathology, legal pathology, economic pathology, aesthetic pathology, environmental pathology and infra-structure pathology has been organized. Keywords Environmental Advertising; Urban Identity; Tehran Metropolis; Pathology

\section{I T A T I O N L I N K S}

[Abbasi, et al.; 2009] Qualitative research on the effect ...; [Abouei Ardakan, et al.; 2014] Identifying the critical factors ...; [Ahmadi; 2010] Environmental advertising ...; [Bashiru \& Bunyaminu; 2013] A critical analysis on advertising ...; [Bonyanian; 1998] A model on the pathology ...; [Braun \& Clarke; 2006] Using thematic ...; [Chan \& Cheng; 2012] Awareness of outdoor ...; [Chervin; 2011] Environmental advertising in the ...; [Defleur \& Dennis; 2013] Understanding mass ...; [Fourie; 2008] Media studies: Media history, media ...; [Ghafouri \& Asghari; 2012] Advertising urban morphology ...; [Ghalenoi, et al; 2011] The role of shop floorboards in changing ...; [Gidens; 2017] Ociology ...; [Gray, et al; 2007] The research imagination: An ...; [Hasanrezaei; 2016] The broken window theory ...; [Heidari, et al.; 2017] Study and evaluation of environmental ...; [Hesse-Biber \& Leavy; 2003] Approaches to qualitative research ...; [Kelling \& Wilson; 2003] Broken windows: The police and ...; [Kim \& Jun; 2016] The impact of event advertising on attitudes ...; [King \& Horrocks; 2010] Interviews in qualitative ...; [Kvale; 1996] An introduction to quantitative ...; [Mahdizadeh; 2012] Media theories: Common ...; [Majidi Ghahroodi \& Abbasi; 2012] The role of environmental ...; [Mcquail; 2010] Mcquail's mass communication ...; [Mohammadian \& Pourhosseini; 2012] Qualitative research method, anti-method ...; [Mohammadpour; 2013] Qualitative research method ...; [Mokhtari Naseri, et al.; 2015] The effect of environmental advertising ...; [Moradi; 2014] Paradigm shift from ...; [Nazeri, et al; 2016] Evaluation of effectiveness factors ...; [Payandeh; 2006] A critical reading ...; [Postman; 2015] Life in sash, dying in ...; [Poulos \& Pasch; 2015] The Outdoor MEDIA DOT ...; [Ritzer; 2015] Theories of sociology in ...; [Sajjadi; 2011] Advertising ...; [Salehi Amiri; 2016] Concepts and Cultural ...; [Seidman; 2006] Interviewing as qualitative ...; [Terkan; 2014] Importance of creative advertising ...; [Valkenburg; 2000] Media and youth ... 
Ilali S.H. MA

Nami M. MA

Hoseini Amin S. N. PhD

Boroujerdi Alavi M. PhD

Ha.ilali@yahoo.com

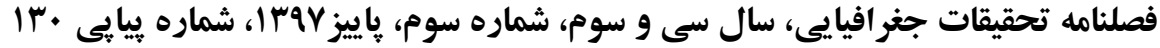

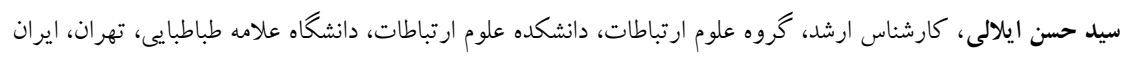

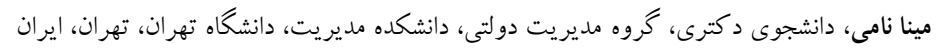

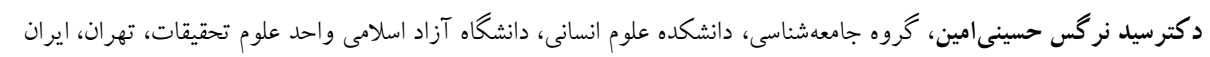

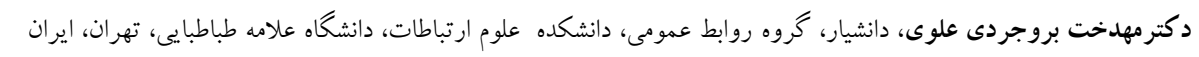

\section{آسيبشناسى مديريت تبليغات محيطى كلانشهر تهران}

مقدمه: هر آنجه در فضاى شهرى قرار مى گيرد، به نحوى بر زيبايى، شيوه زيست، فرهنگ، عادات و رفتارهاى شهروندان و

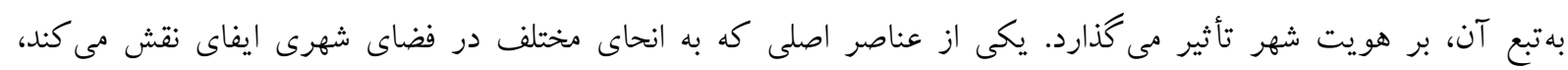

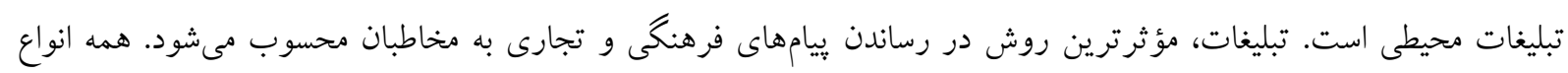

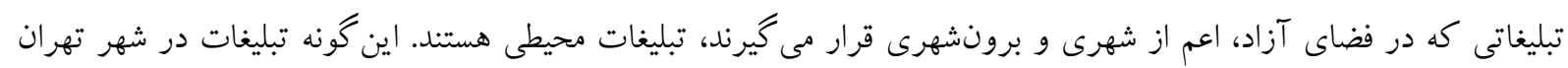

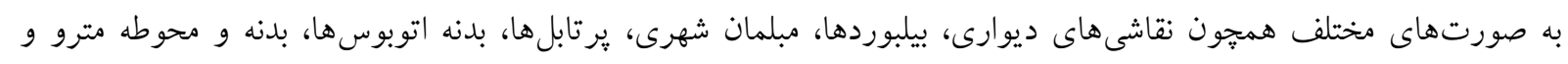

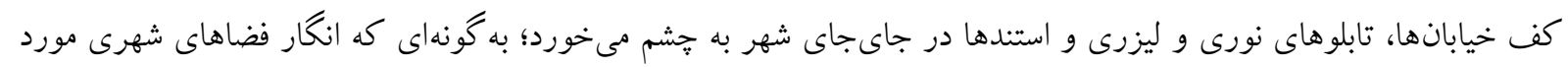

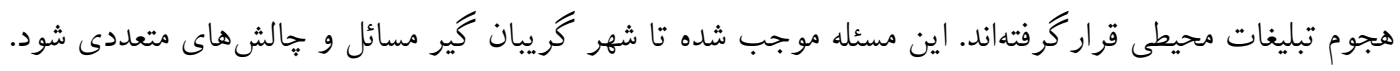
اهداف: هدف تحقيق حاضر شناسايى مهمترين آسيبهاى ناشى از مديريت تبليغات محيطى در شهر تهران است.

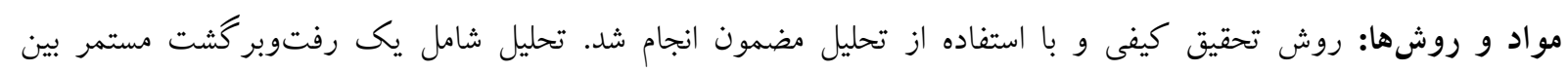

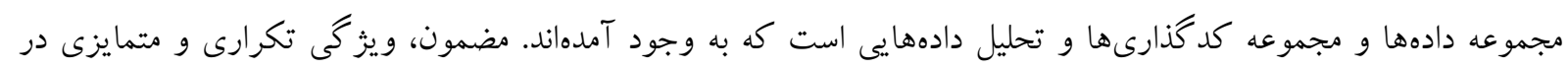

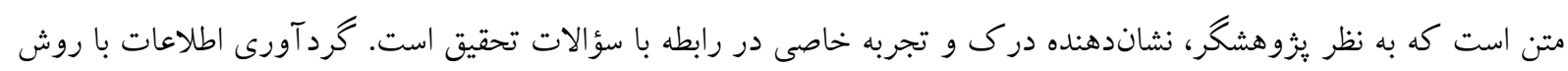

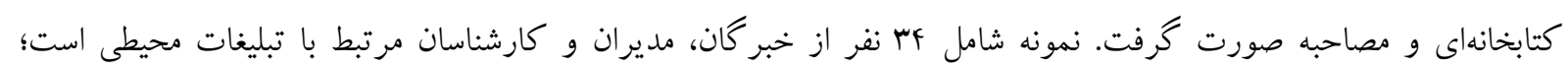

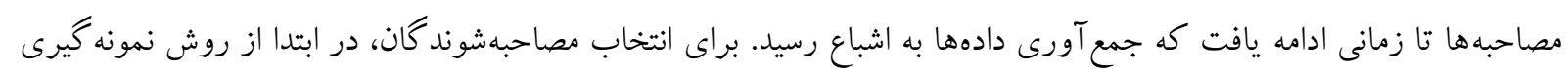

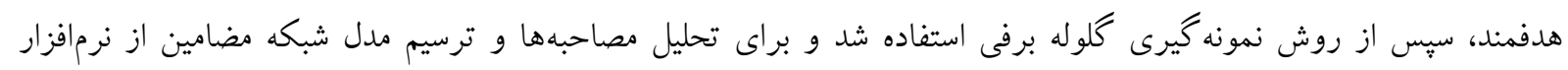
MAXQDA نتيجه گيرى: يافتها در ^ مضمون اصلى: آسيبهاى مديريتى، آسيبهاى فرهنكى - اجتماعى، آسيبهاى روانشناختى،

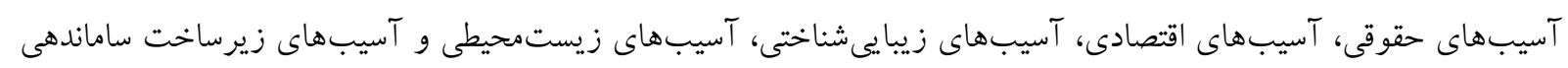


امروزه تبليغات، مؤثرترين روش در رساندن بيام بنگاههاى تجارى به مخاطبان محسوب مىشود (Kim \& Jun, 2016).

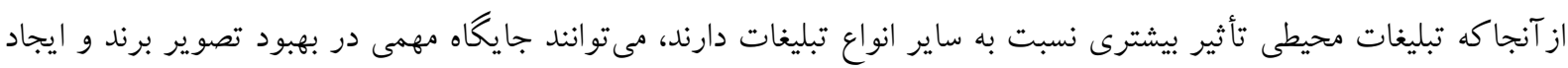

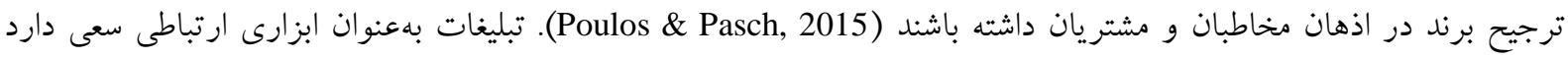

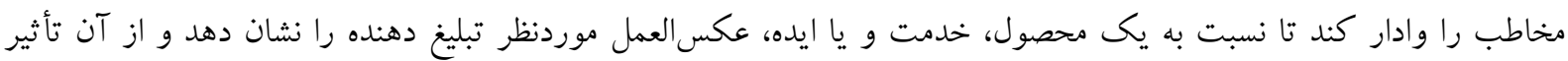

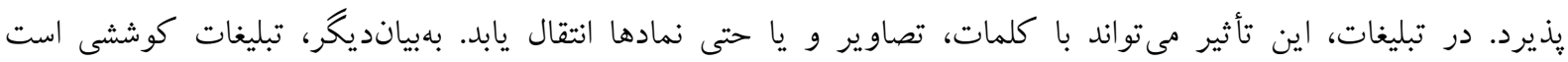

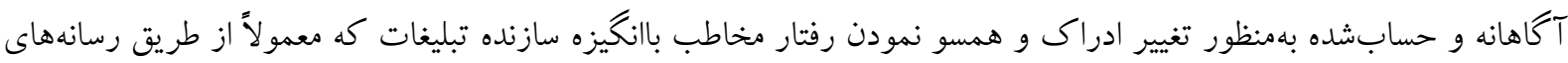

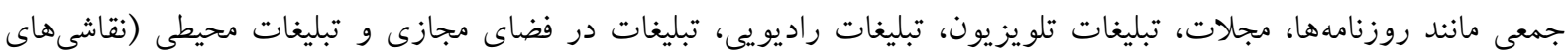

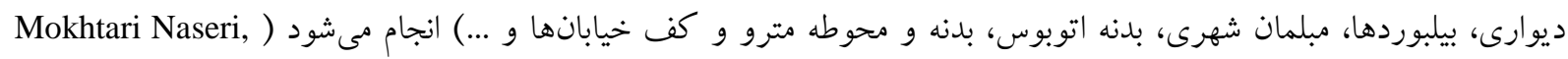

.(Hassanpour, \& Khatayi, 2015 ضرورت انجام تبليغات محيطى امرى غيرقابلانكار است اما تهران مورد هجوم تبليغات محيطى است كه بدون هماهنكى در

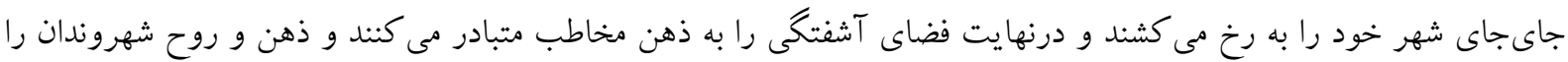

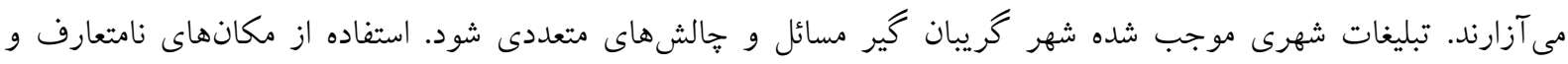

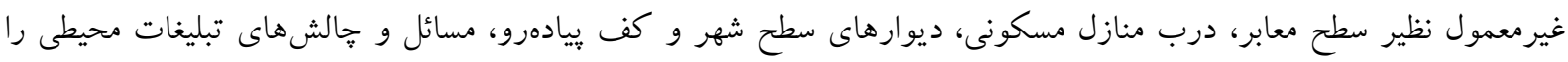

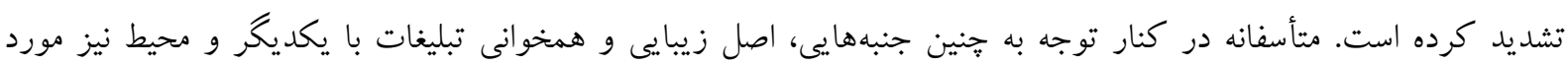

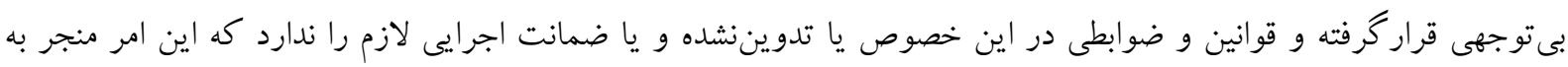

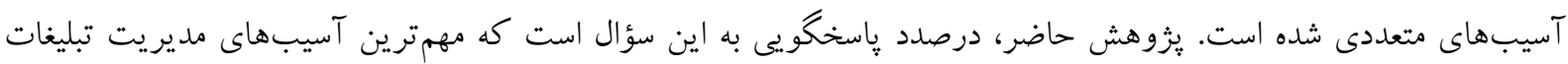
محيطى در شهر تهران קيست. تحقيقات جامع و منسجم در خصوص وضعيت تبليغات محيطى در ايران و آسيبها و كاستىهاى ناشى از آن حاكى از

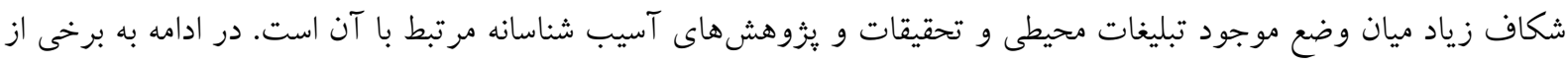
مطالعات در اين مهم اشاره مىشود: حيدرى و همكاران در مطالعهاى به ارزيابى و اولويتبندى ميزان اغتشاش مؤلفه هاى شاخص تبليغات مات محيطى در محدوده

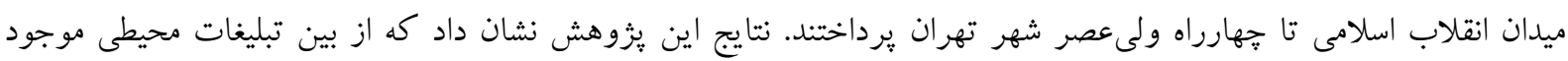

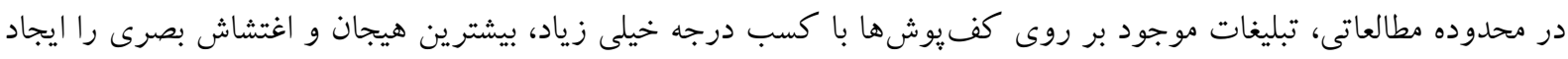

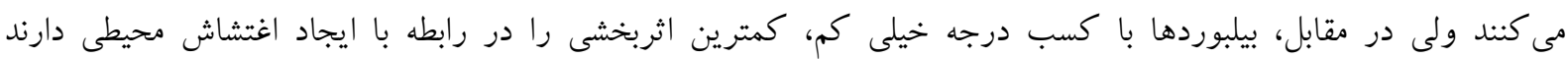
.(Heidari, Zebardast, \& Asgari Rad, 2017)

مجيدى قهرودى و عباسى به نقش تبليغات محيطى (تبليغات بدنه اتوبوسهاى درونشهرى) بر ترغيب مخاطب به خريد كالا

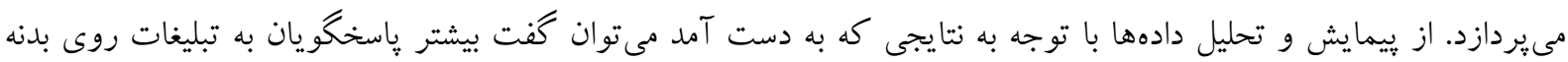

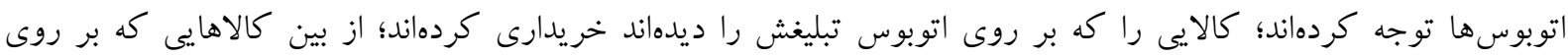

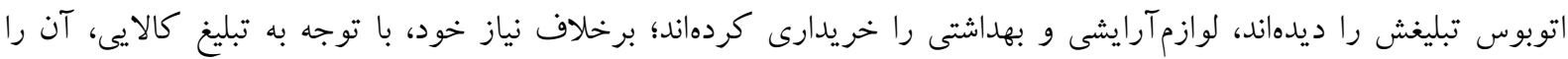

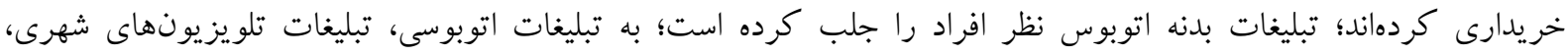

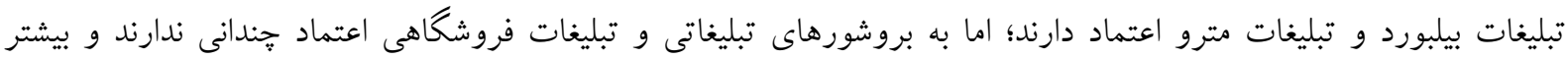

افراد اعتقاددارند كه محور اصلى تبليغات اتوبوسى ترغيب به خريد كالا است (Majidi Ghahroodi \& Abbasi, 2012). 


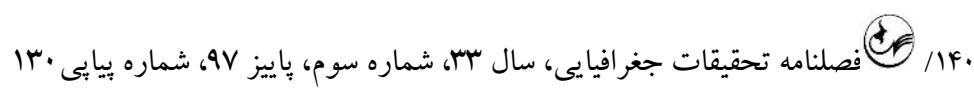

غفورى و اصغرى در كتاب خود با عنوان مورفولوزى شهرى تبليغات در تهران به بررسى و تحليل يافتن مكان و زمان

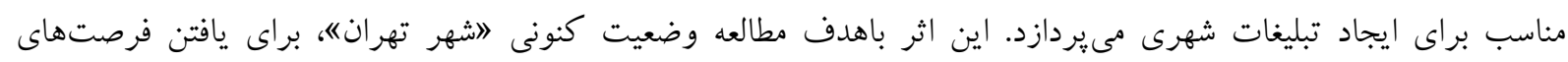

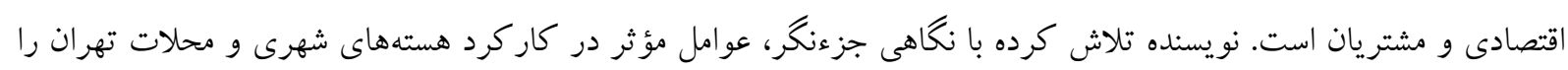

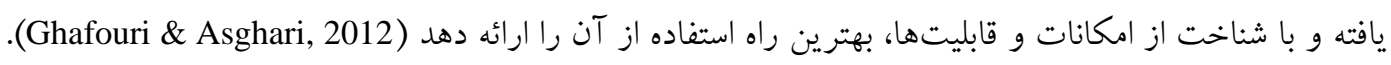

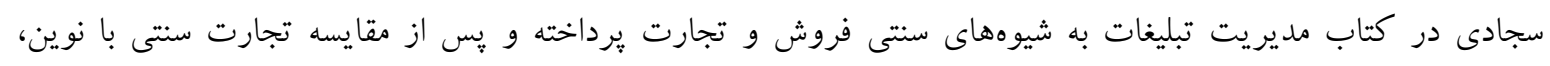

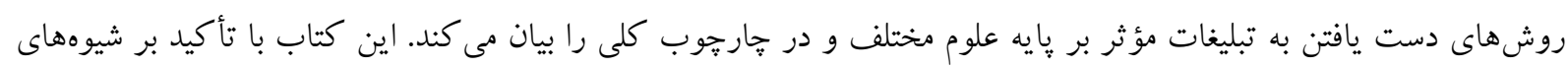

مديريت تبليغات، به تعدد دستخاههاى دخيل در مديريت تبليغات نيز مى يردازد (Sajjadi, 2011). قلعنويى و همكاران در مقاله نقش تابلوهاى تبليغاتى فروشگاهها در تغيير شكل منظره شهرى (مورد مطالعاتى: خيابان

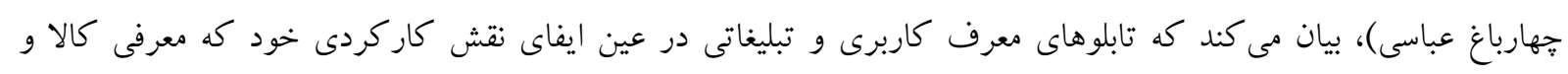

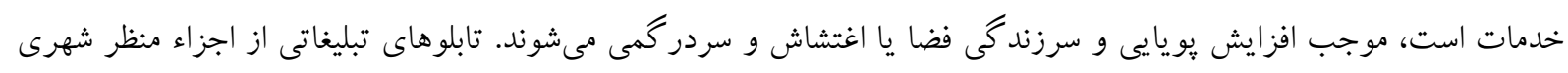

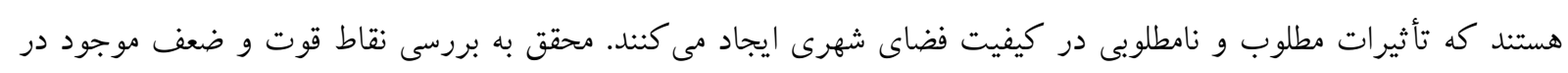

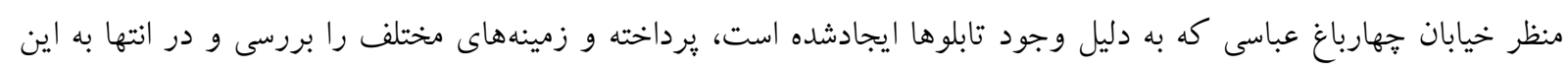

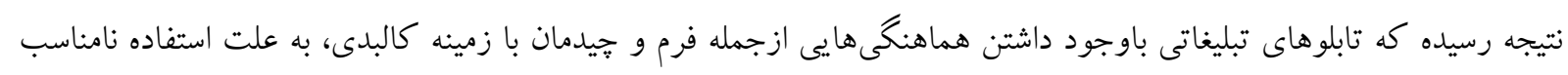

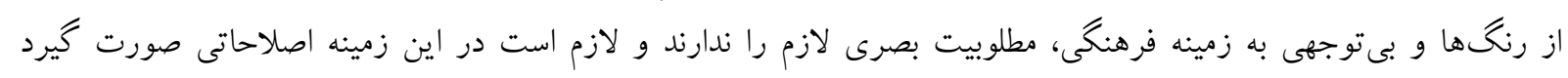

.(Ghalenoi, Bahramian, \& Madani, 2011)

احمدى در كتاب خود با عنوان مهندسى تبليغات محيطى به رابطه سطحى صنعت تبليغات، بهخصوص تبليغات محيطى در

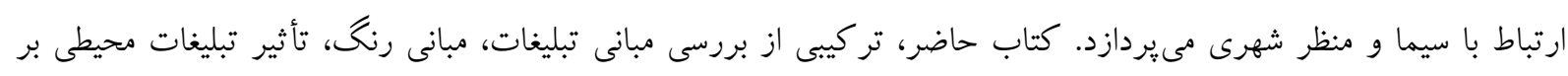

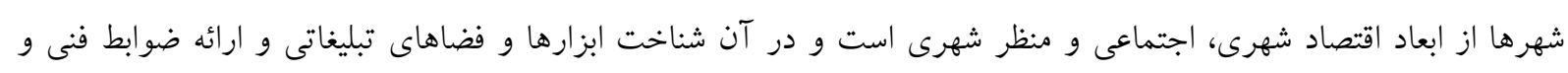

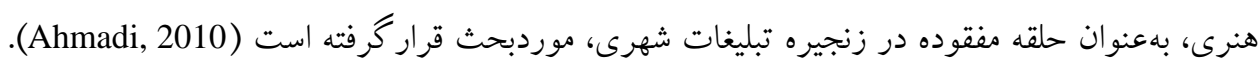

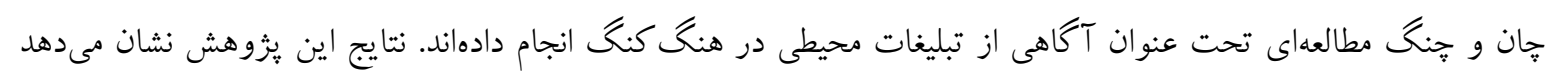

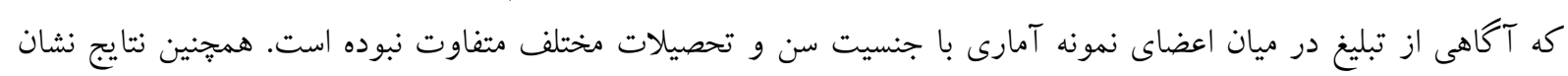

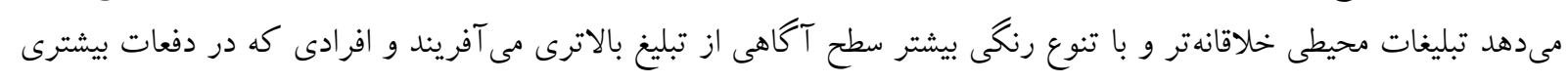
با تبليغ روبهرو مىشوند نيز تحت آكاهى بالاترى از تبليغ دارند (Chan \& Cheng, 2012).

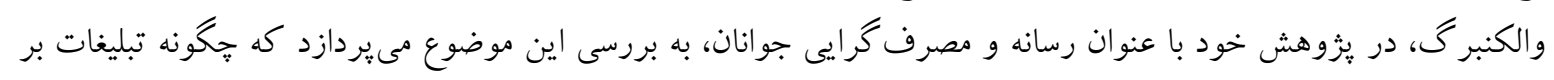

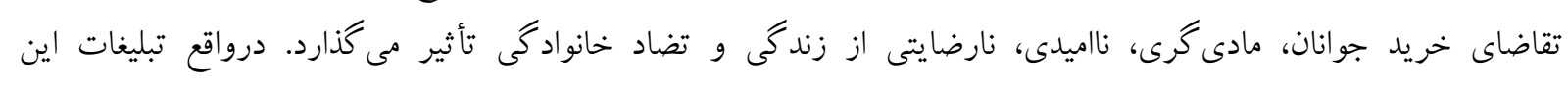

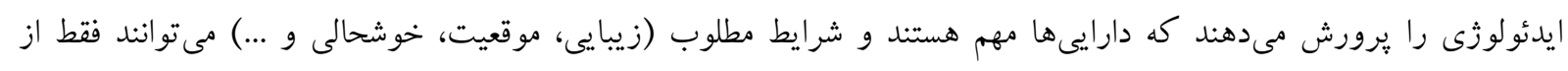

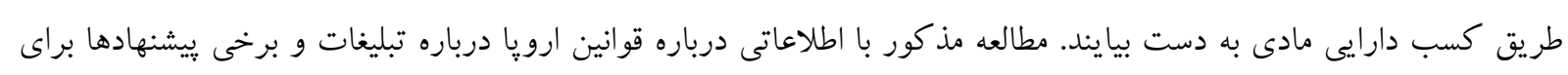
تحقيق در مورد رفتار مصرف كننده كود كان به بايان مىرسد (Valkenburg, 2000).

مواد و روشها

در تحقيق حاضر از روش كيفى استفادهشده است. دادهاى تحقيق كيفى از طريق مشاهده و مصاحبه كردآورىشده و

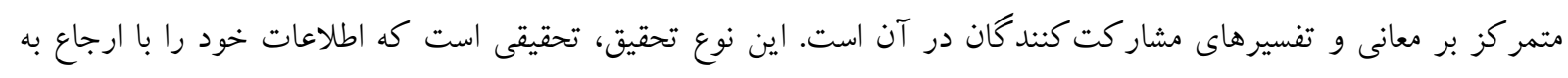

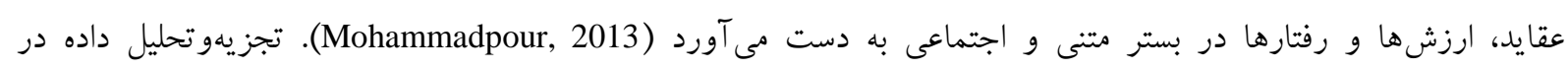

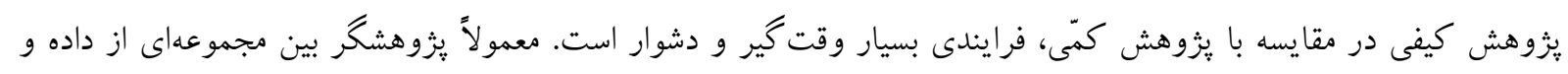


تحليل داده بهطور مداوم به عقب و جلو حر كت مى كند، بهعبارتديگر او فرايندى تكرارى را دنبال مى كند (Moradi, 2014).

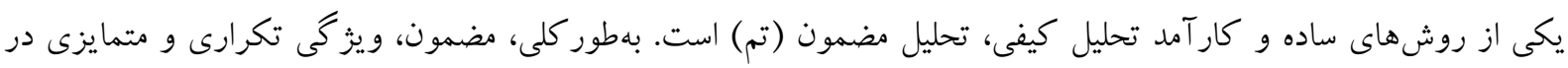

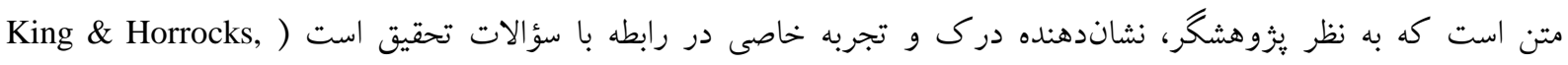

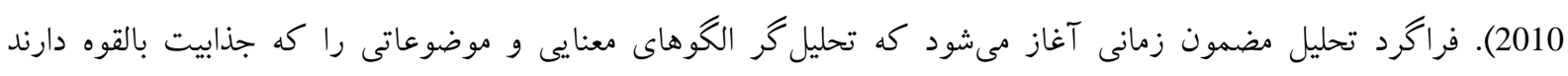

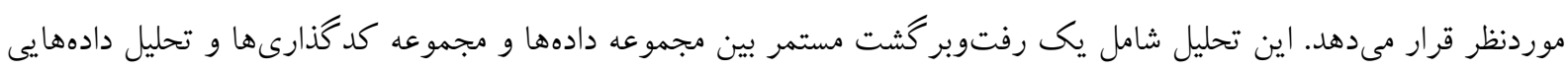

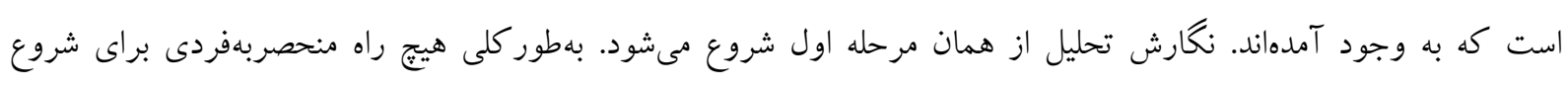

مطالعه در مورد تحليل مضمون وجود ندارد (Braun \& Clarke, 2006).

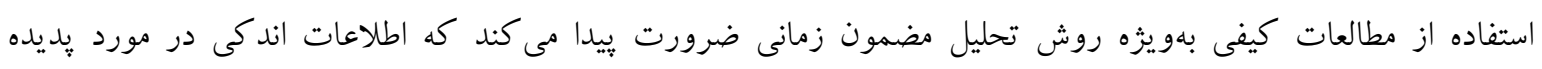

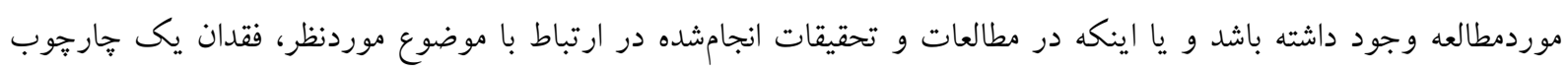
نظرى كه بهصورت جامع به تبيين موضوع بيردازد، مشهود باشد) (Abouei Ardakan, Labafi, Azarpour, \& Jalalpur, 2014).

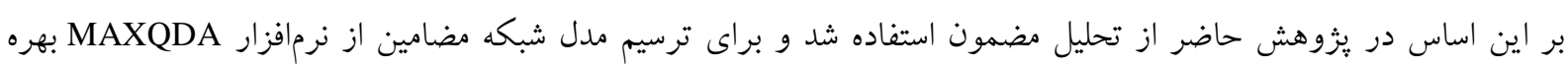
كرفته شد.

جامعه آمارى اين يزوهش را اساتيد، كارشناسان و خبر كان در حوزه تبليغات محيطى تشكيل مىدهد و نمونه موردنظر شامل

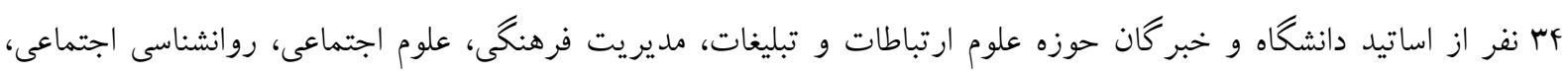

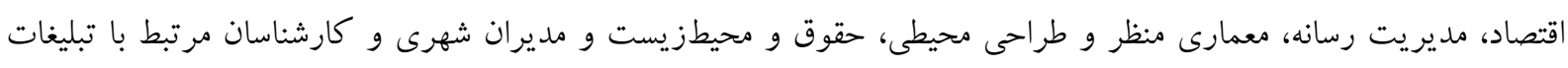

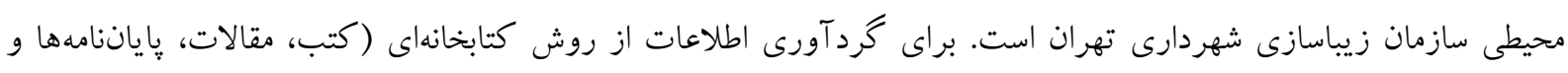

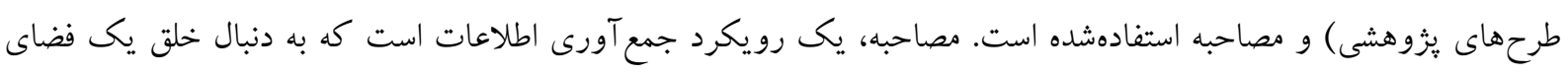

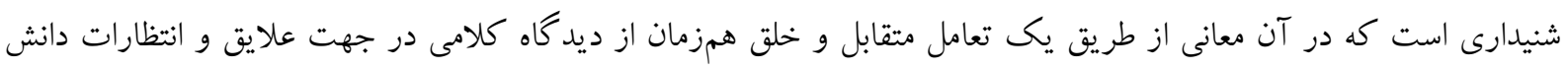

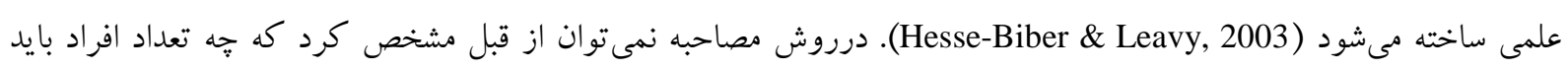

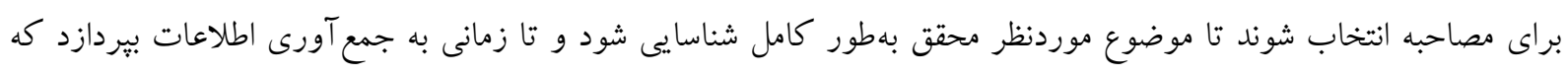

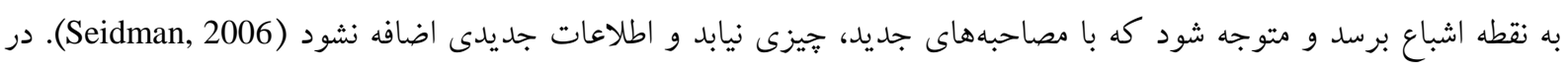

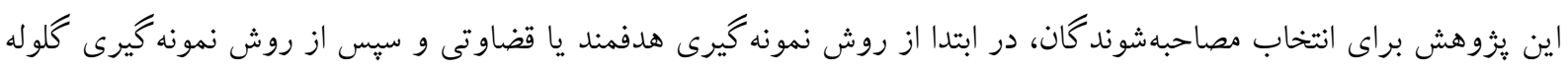

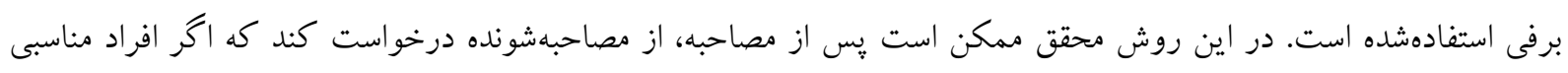

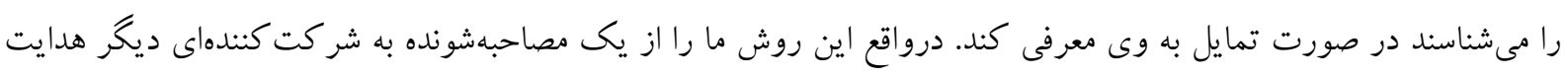

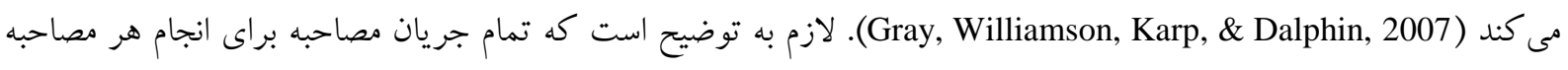

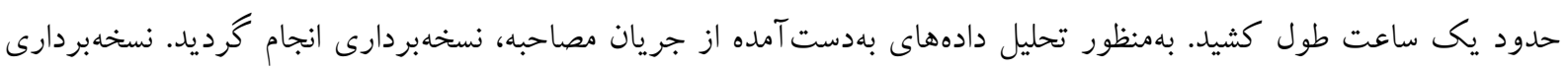

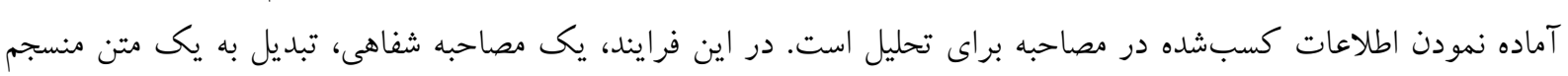

مى گردد (Abbasi, Gholipour, Delavare, \& Jafari, 2009).

بررسى اعتبار و پِايايى

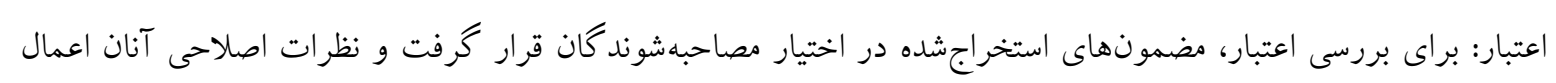

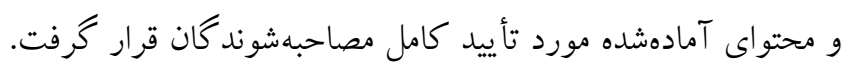




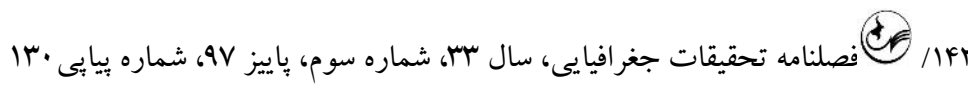
پايايى: براى محاسبه پايايیى مصاحبه با روش توافق درون موضوعى دو كدگذار درخواست شد تا سه مصاحبه را به همراه

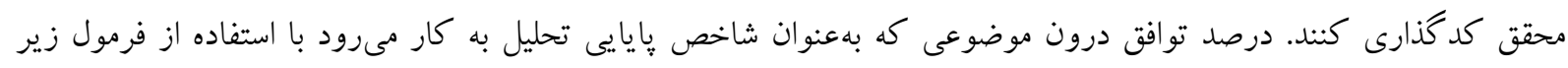
محاسبه شد:

$$
\text { درصد توافق درون موضوعى }=\frac{2 M}{\mathrm{~N} 1+\mathrm{N} 2} \times 1 \text {. . }
$$

جدول 1 - مدحاسبه هايايى بين دو كد تعذار

\begin{tabular}{|c|c|c|c|c|}
\hline קايايى بين دو كد گذار (درصد) & تعداد عدم توافقات & تعداد توافقات & تعداد كل كدها & عنوان مصاحبه \\
\hline VV & $r$ & 10 & $r q$ & مصاحبه F \\
\hline va & $\Delta$ & ir & r & مصاحبه 1 \\
\hline VV & f & 1. & rs & مصاحبه q9 \\
\hline VV & ir & щ & 91 & تعداد كل \\
\hline
\end{tabular}

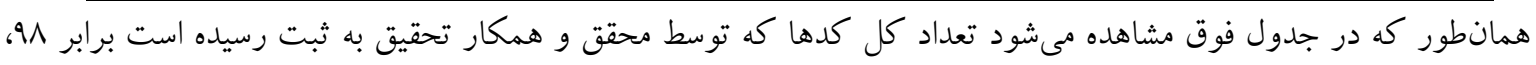

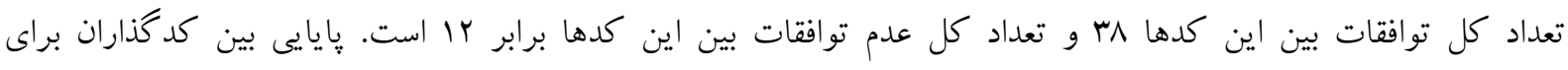

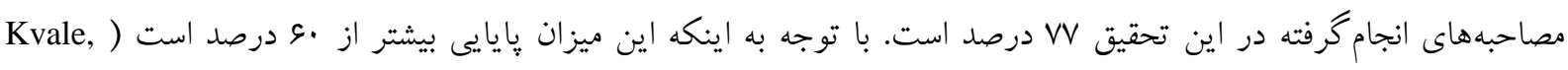

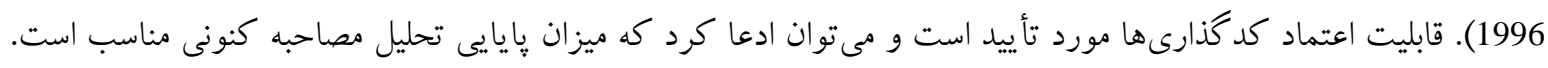

\section{ادبيات نظرى تحقيق}

تبليغات شكلى از فعالسازى ارتباطات است كه مىتواند براى متقاعد كردن مصرف كنند كان براى خريد كالاها و خدمات

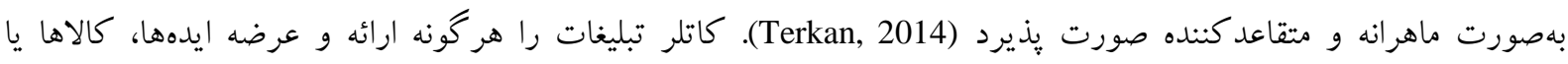

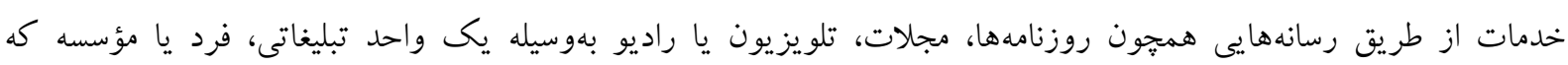

مستلزم يرداخت هزينه باشد، تعريف مى كند (Bashiru \& Bunyaminu, 2013).

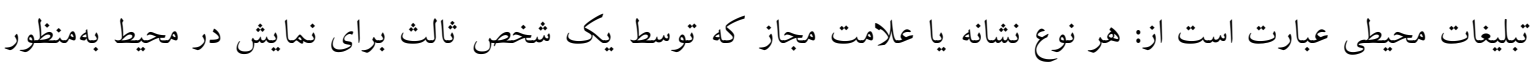

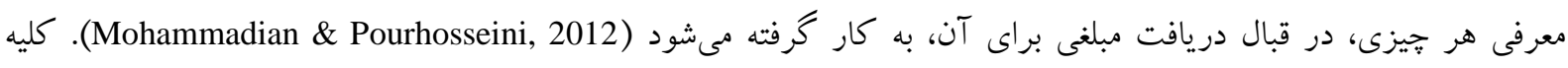

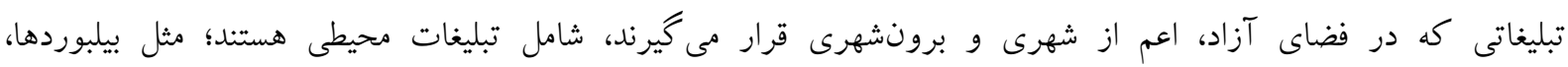
تلويزيونهاى شهرى و مواردى ازايندست (Nazeri, Sobhanifard, \& Ettehad mohkam, 2016).

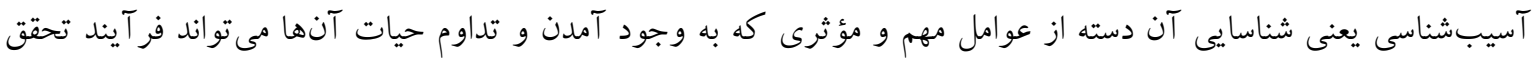
اهداف هر سيستمى را متوقف و يا بهصورت محسوس، كُند نمايد (Bonyanian, 1998).

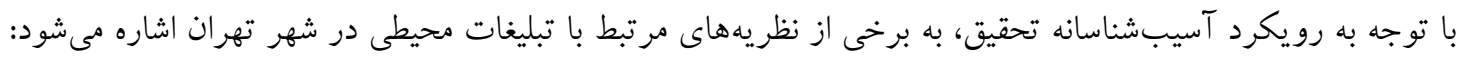

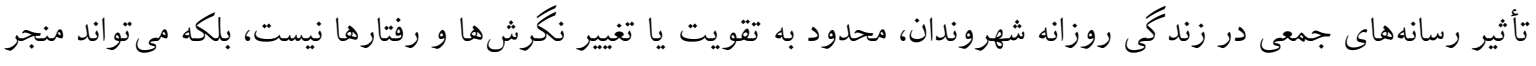

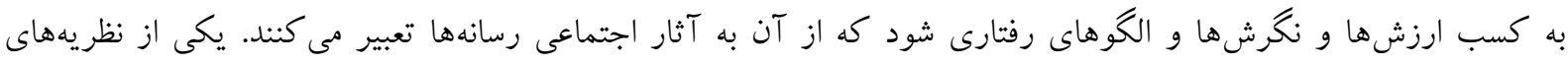

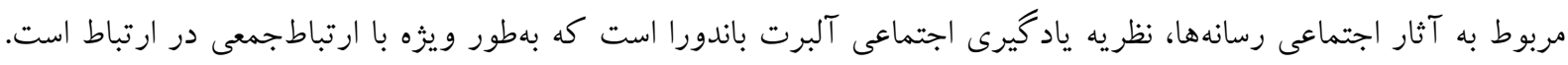

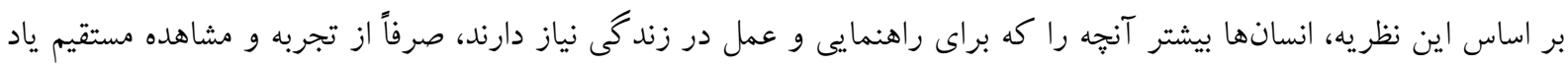

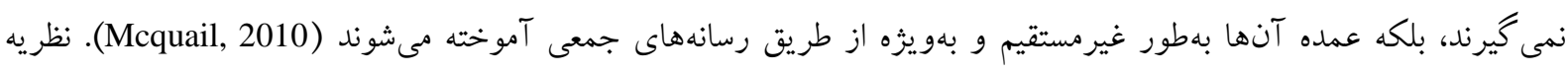

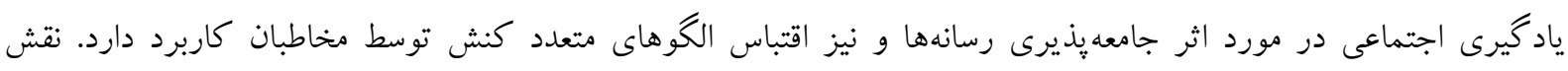

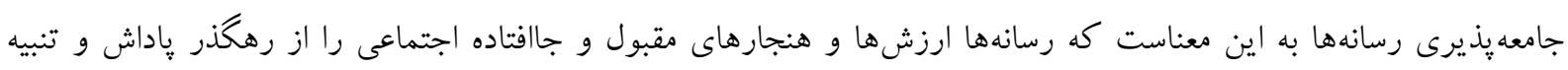




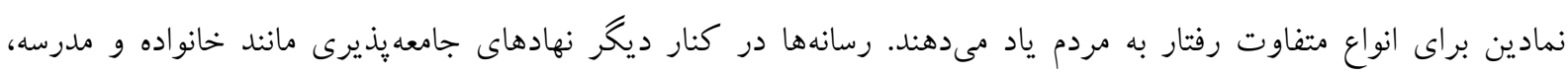

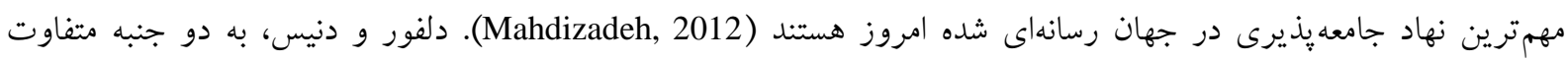

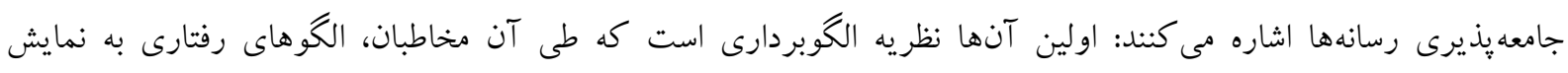

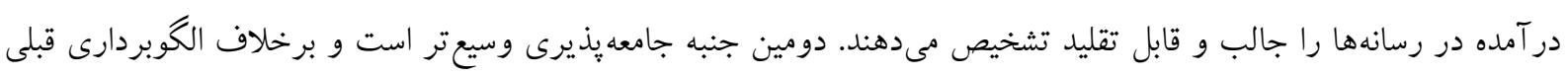

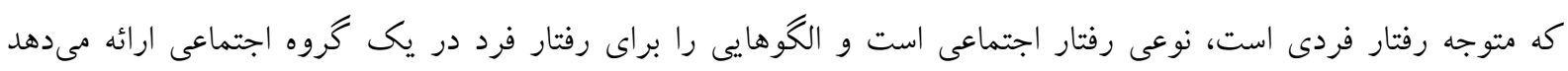

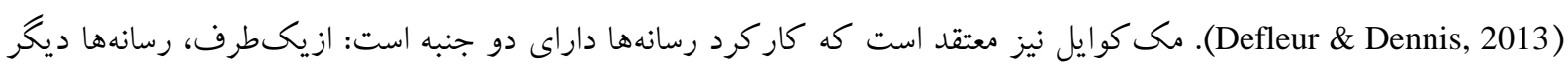

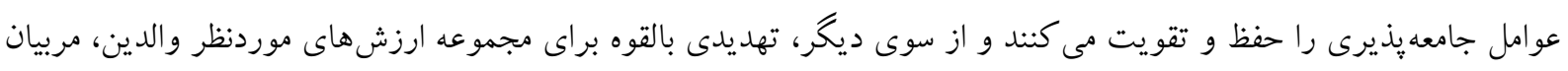
و ديخر عوامل كنترل اجتماعى هستند (Mcquail, 2010).

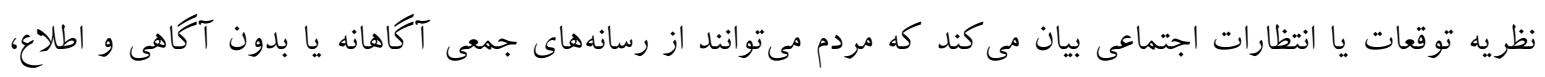

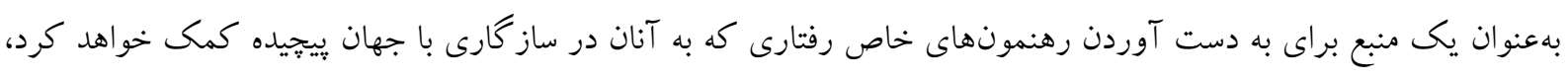

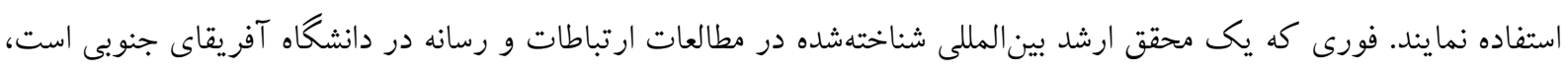

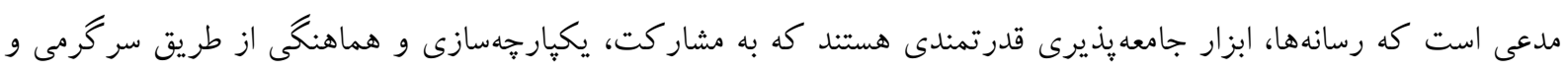

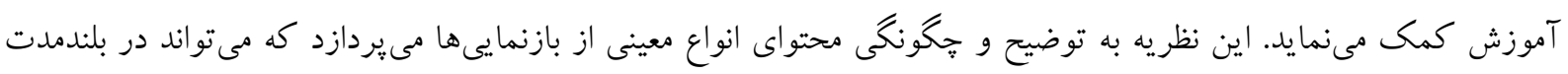

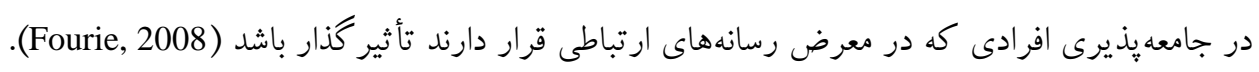

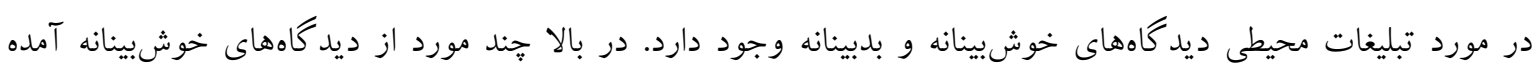

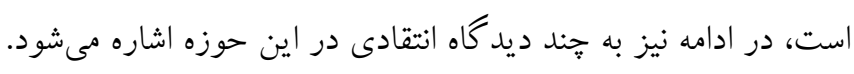

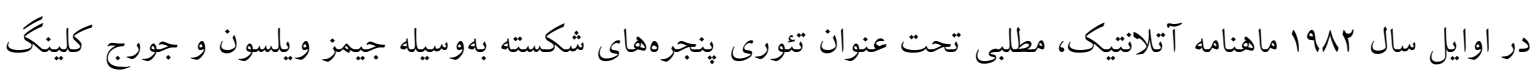

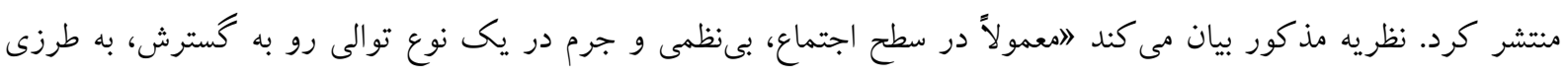

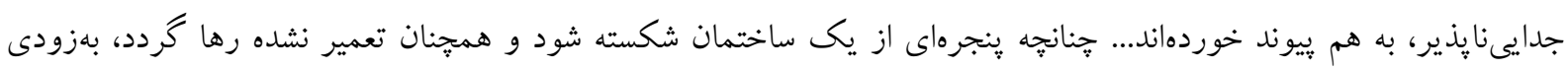

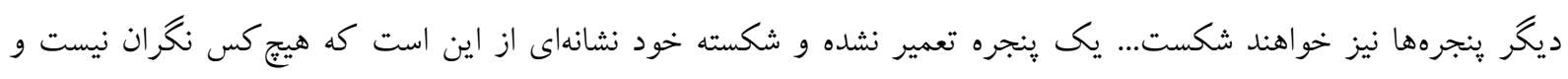

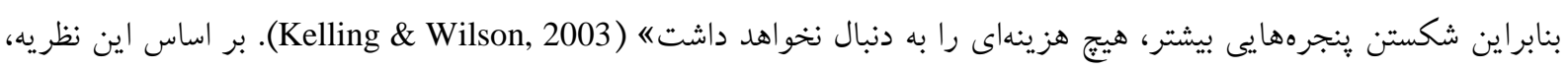

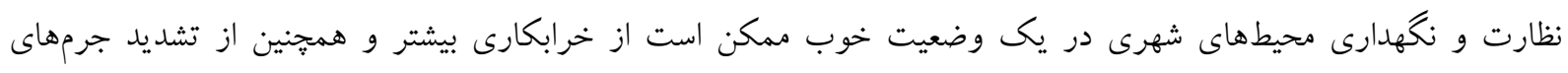

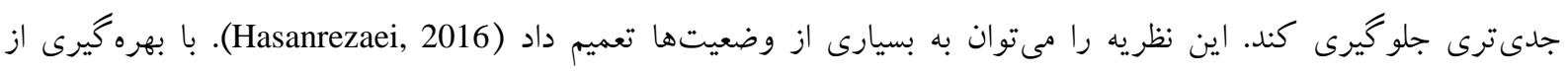

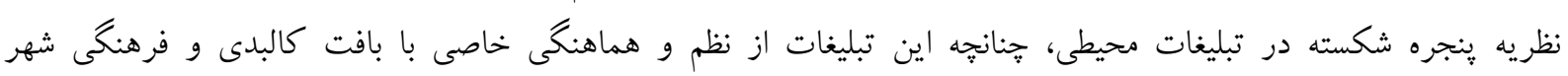

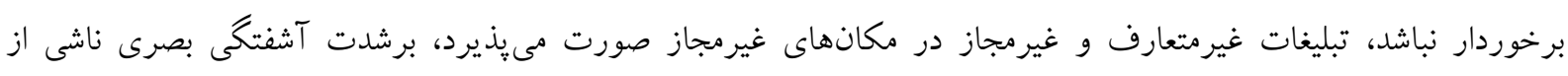

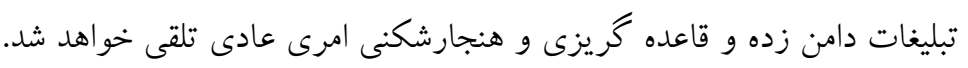

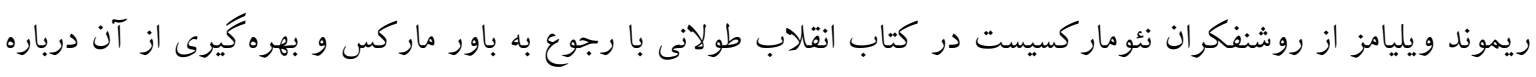

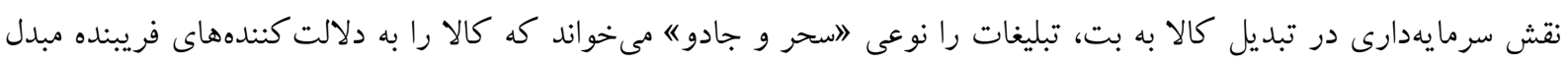

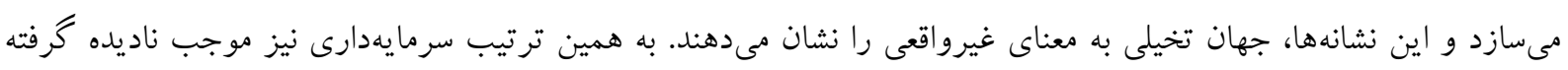

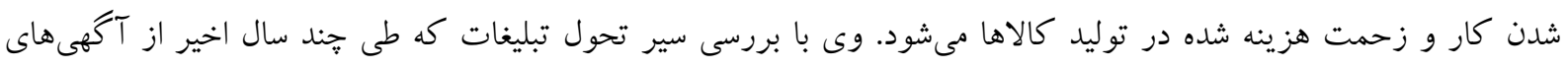

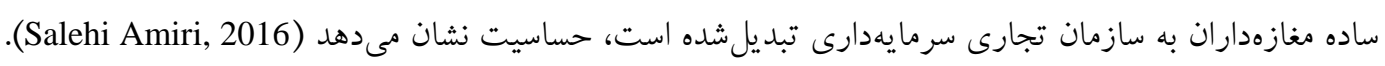

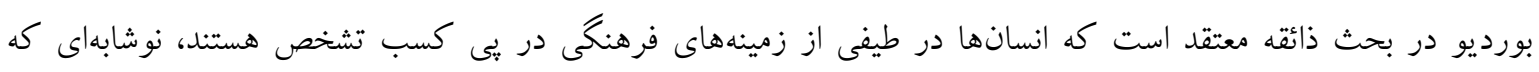

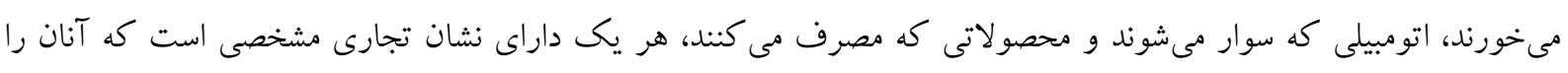

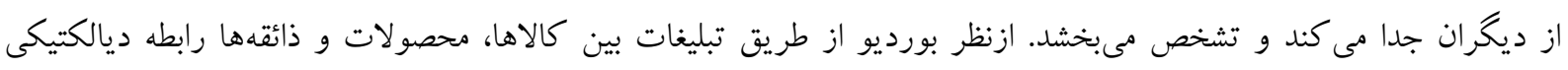




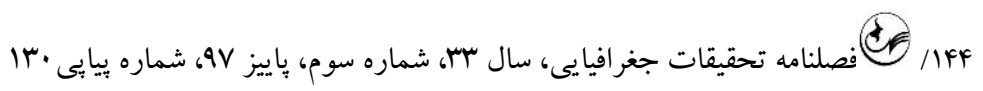

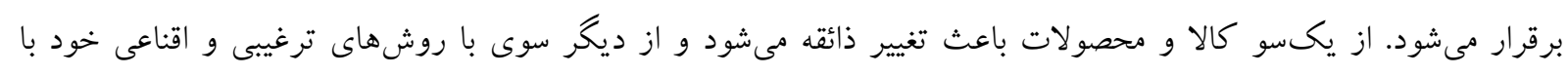

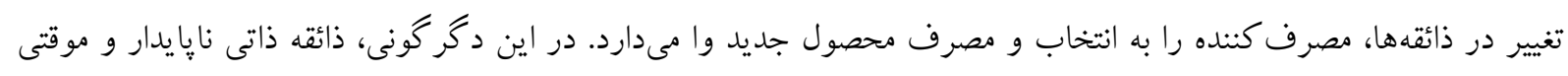
دارد و بهطور دائم اين رابطه ديالكتيكى توليد و بازسازى مىشود؛ جان كلام اين كه سرمايه مولد سرمايه مى شود (Ritzer, 2015).

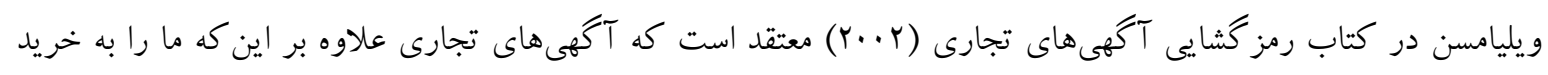

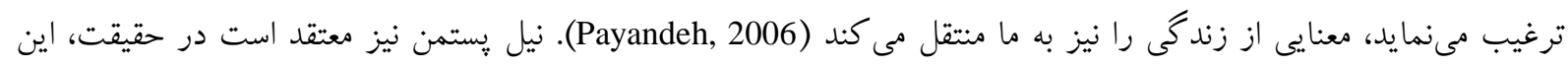

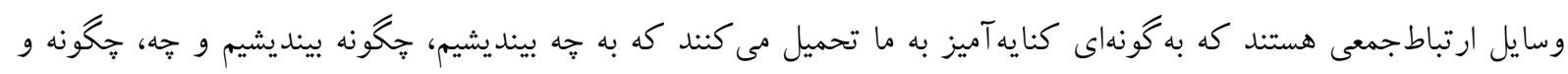

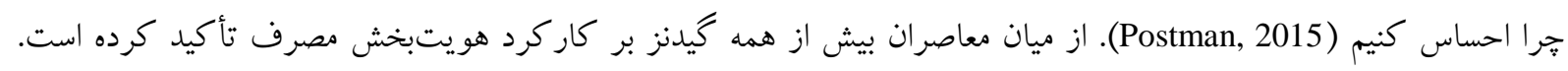

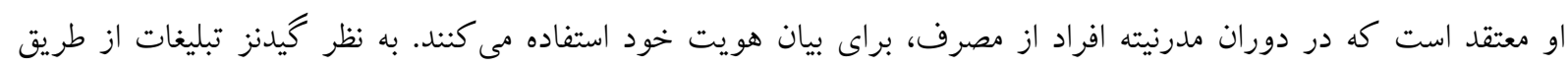

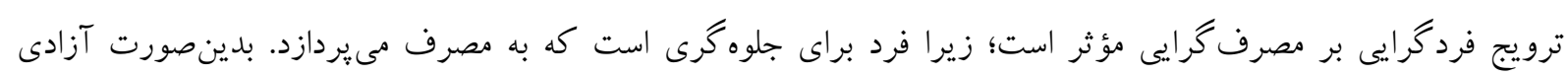

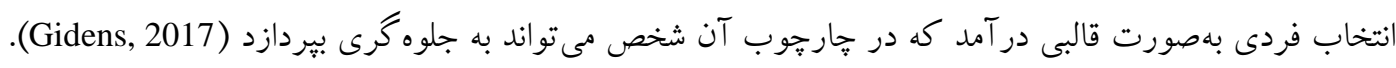

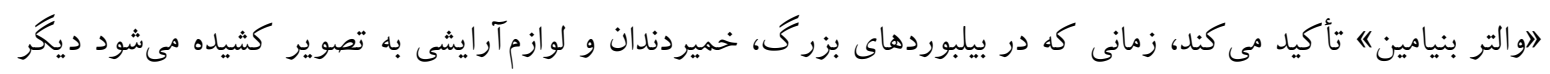

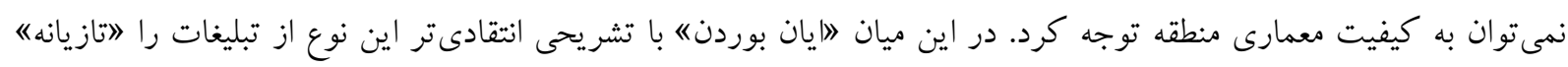

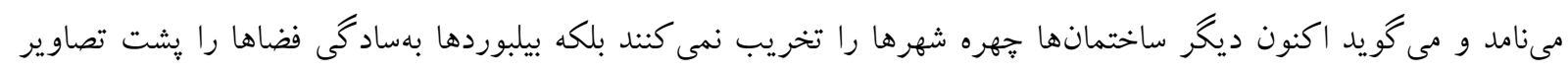

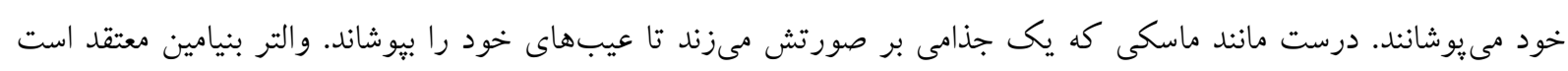

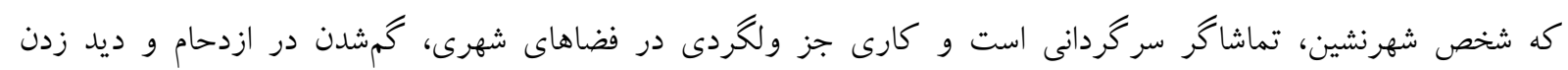

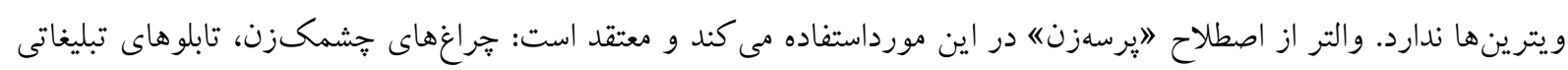

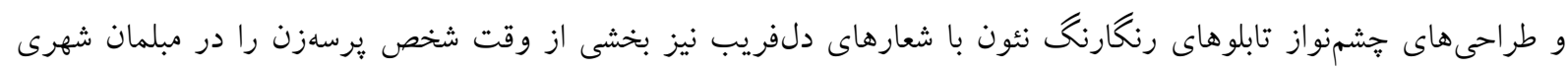
بهخوبى يُر مى كند (Chervin, 2011).

\section{نتيجه كيرى}

مصاحبهشوندكان در پاسخ به سؤال نوع آسيبى كه تبليغات شهرى وارد مى كنند، به آسيبهاى مختلف اشاره كردند كه در

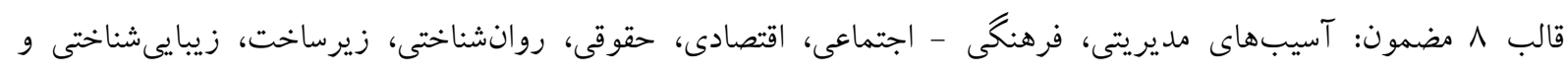

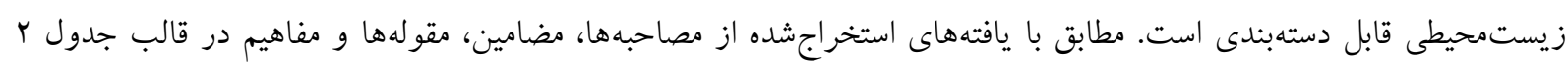




\section{جدول r - مقوله ها و مفاهيم تبليغات شهرى مربوط به انواع آسيبها}

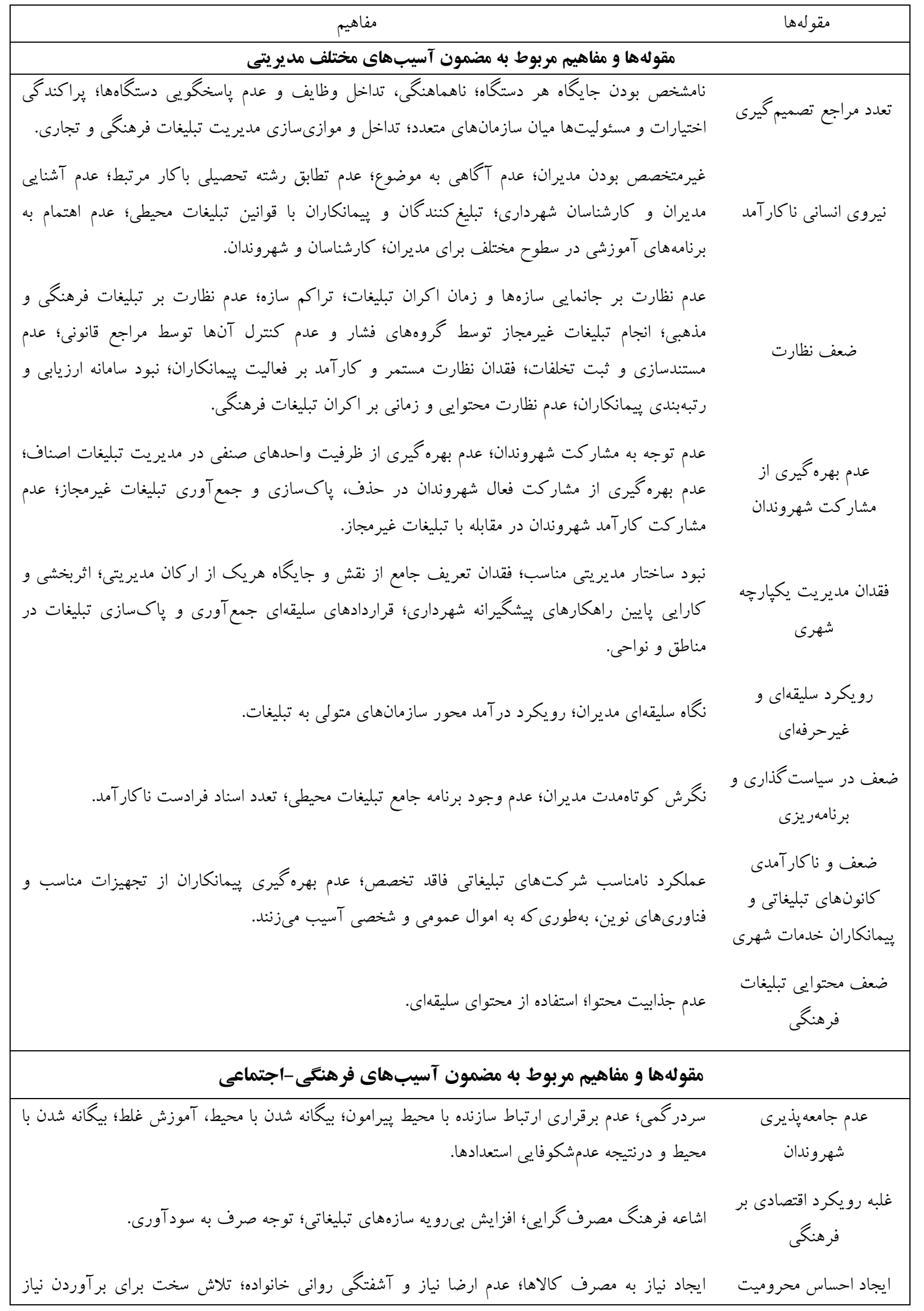




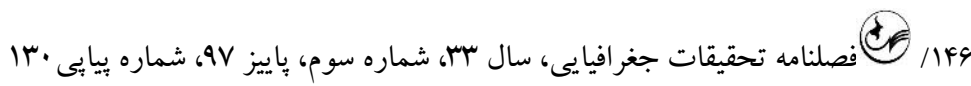

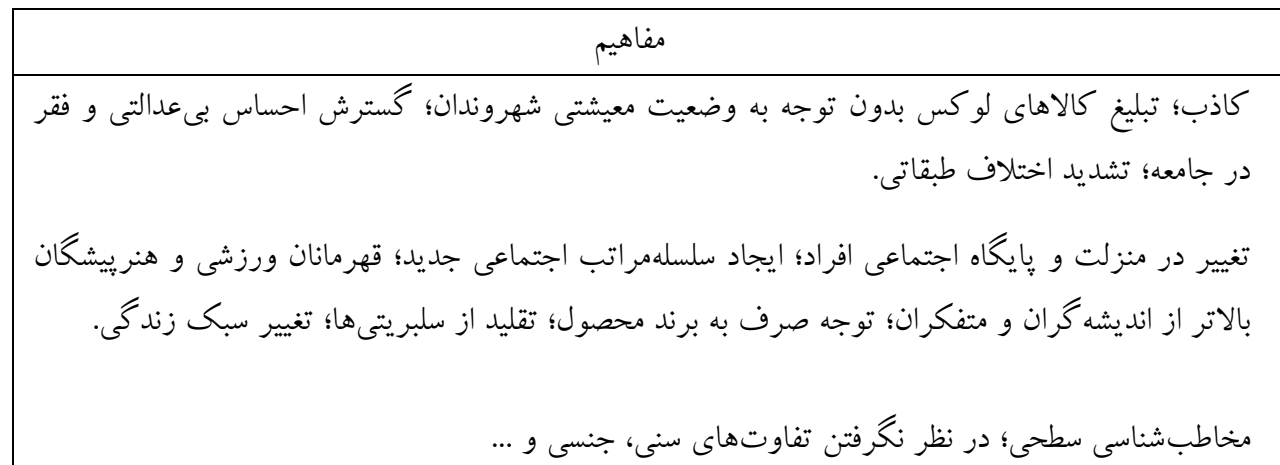

اغلب تبليغات هيج ييام خاصى ندارند؛ ضعف محتوايى تبليغات محيطى؛ تضادهاى تبليغاتى و تشويق همزمان

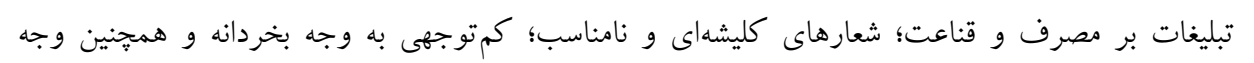

$$
\text { اخلاقى در تبليغ و اهميت بيشازحد به وجه احساسى. }
$$

ييامهاى فرهنكى سطحى؛ جنبه نصيحتى بودن تبليغات؛ كليشهاى و تكرارى بودن محتوا؛ عدم خلاقيت و

$$
\text { نو آورى در توليد محتوا. }
$$

تشديد اختلاف نسل جديد و قديم؛ دگرگ گُى ارزشها.

الخوبردارى نادرست از

كروههاى مرجع

عدم توجه به تفاوتهاى

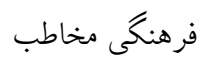

بى محتو ايى تبليغات محيطى

عدم اثربخشى تبليغات

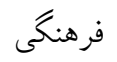

تشديد شكاف نسلى

تخريب باورها؛ تبليغ يكشبه يولدار شدن؛ تضعيف هويت ملى و محلى؛ كليشهازى درباره زنان و

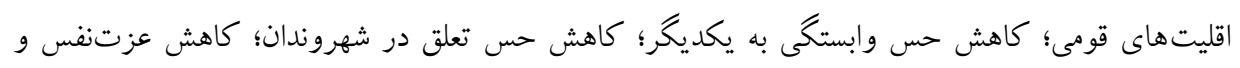
اراده ملى. تضعيف هويت هاى فردى و جمعى

تبليغات غيرمجاز و غيرمتعارف؛ الكوبردارى از متخلفين؛ تعرض به حقوق شهروندان با انجام تبليغ بر روى اماكن خصوصى و عمومى؛ رواج بىقانونى و تشويق مردم به انجام كار غيرمجاز. ترويج قانون گريزى تحريك به تخريب اموال با مشاهده فضاى آشفته و ير از تبليغ غيرمجاز؛ آشفتكى عامل تربيت مردمى آشفته و نامرتب. افزايش ونداليسم

\section{مقولهها و مفاهيم مربوط به مضمون آسيبهاى اقتصادى}

كالاهايى كه تبليغ مىشوند نسبت به كالاهاى مشابه كه تبليغ نمىشوند، هزينه تبليغات را بر روى هزينه توليد مى كشند و آن را از مردم دريافت مى كنند. افزايش قيمت محصولات

صرف هزينه هم براى تبليغ كننده و هم براى كسى كه آن را پاكسازى مى كند، تبليغات مصرف گرايانه

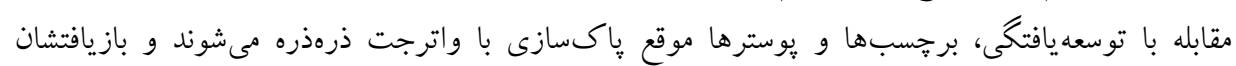
امكانيذير نيست.

حذف يا كمرنخ شدن آيندهنگى، بهوسيله خريد اقساطى و يا دريافت وام براى خريد كالا عملاً حتى از

$$
\text { در آمدهاى آينده نيز برداشت مى شئ شدود. }
$$

حذف يسانداز شهروندان

شر كتهاى توليدى يا خدماتى كه در مقياس كوجٍى فعالاند، به دليل بالا بودن هزينه تبليغات، بهسختى مى توانند در رسانهاى محيطى موجود حضور بيدا كنند.

انحصارى شدن رسانهاى محيطى

كران بودن فضاهاى تبليغات محيطى قانونى، وقتى يك صنف قانونى تبليغ مى كند و هزينه هاى آن را هم به

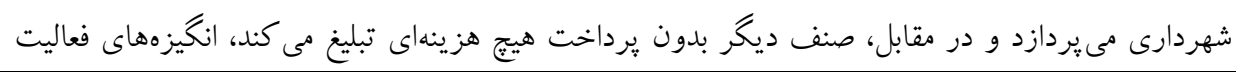
ايجاد فضاى رقابتى ناسالم 


\begin{tabular}{|c|c|}
\hline 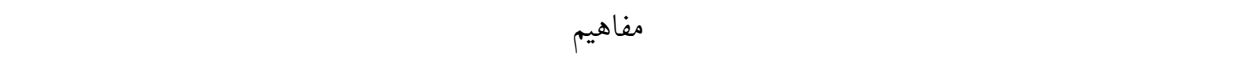 & مقوله ها \\
\hline 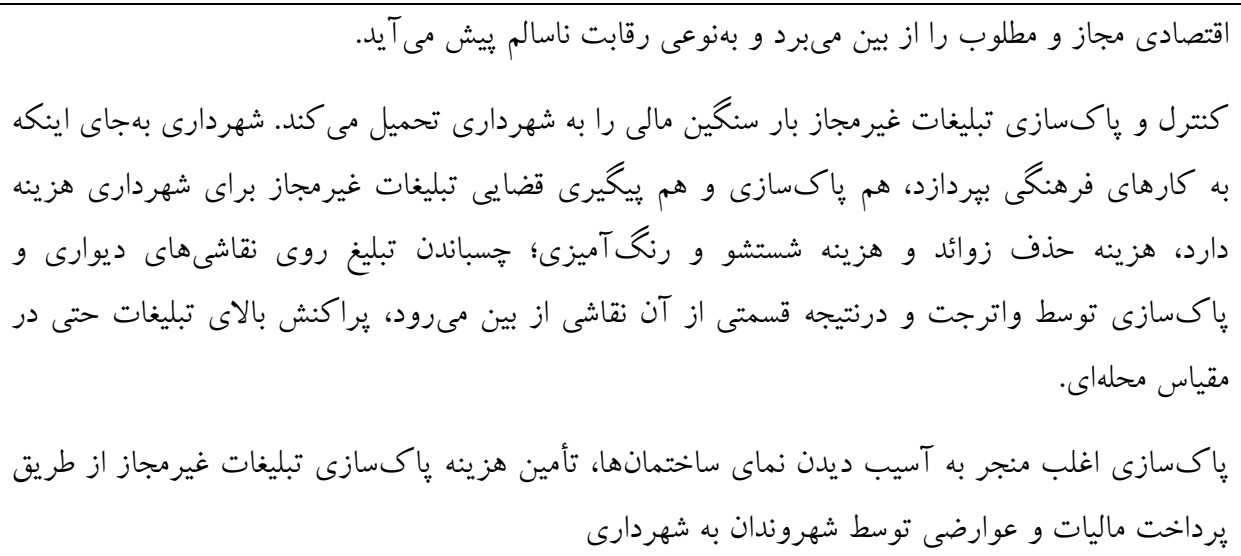 & تحميل هزينه گزاف به شهردارى \\
\hline مقوللها و مفاهيم مربوط به مضمون آسيبهاى حقوقى & \\
\hline 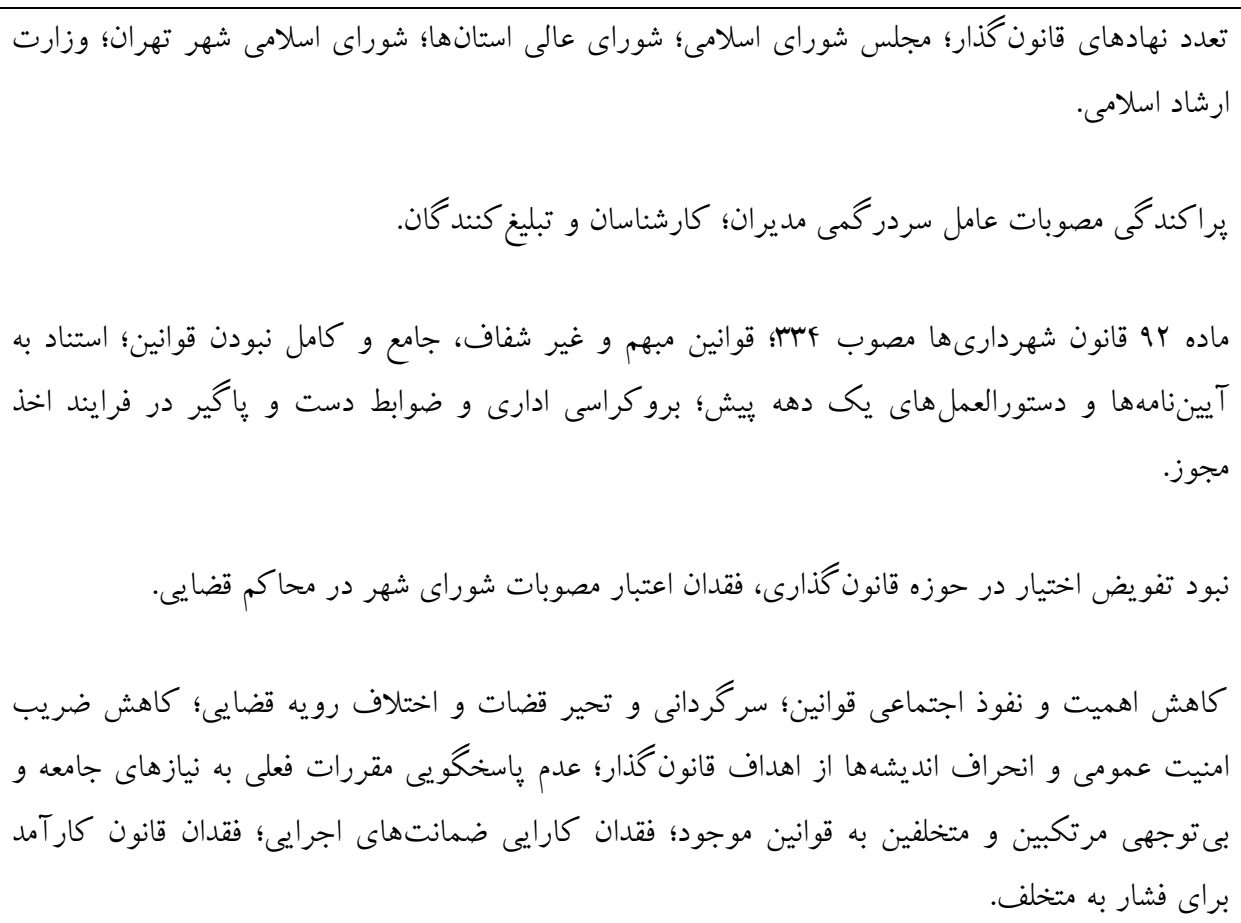 & 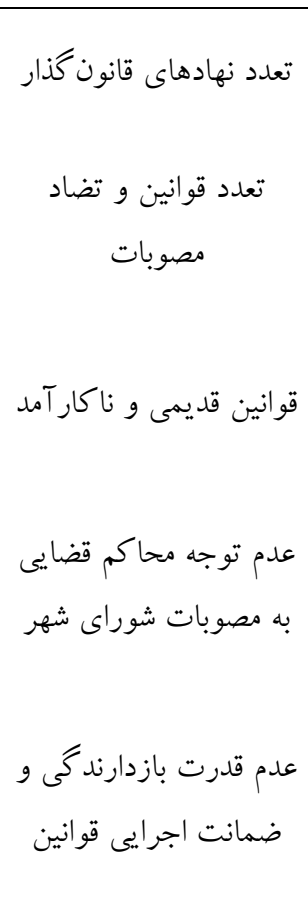 \\
\hline مقوللها و مفاهيم مربوط به مضمون آسيبهاى روانشناختى & \\
\hline تعدد، تنوع و تكرار زياد تبليغات و به كاركيرى شيوهاى تبليغاتى. & 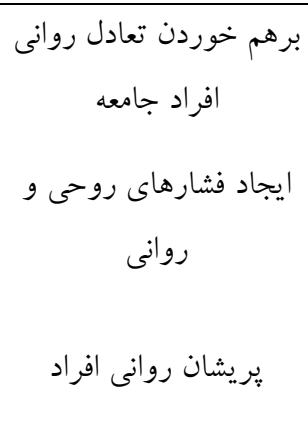 \\
\hline مقوللها و مفاهيم مربوط به مضمون آسيبهاى زيرساخت & \\
\hline 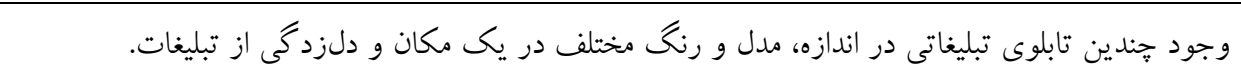 & \\
\hline
\end{tabular}




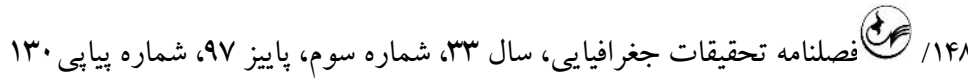

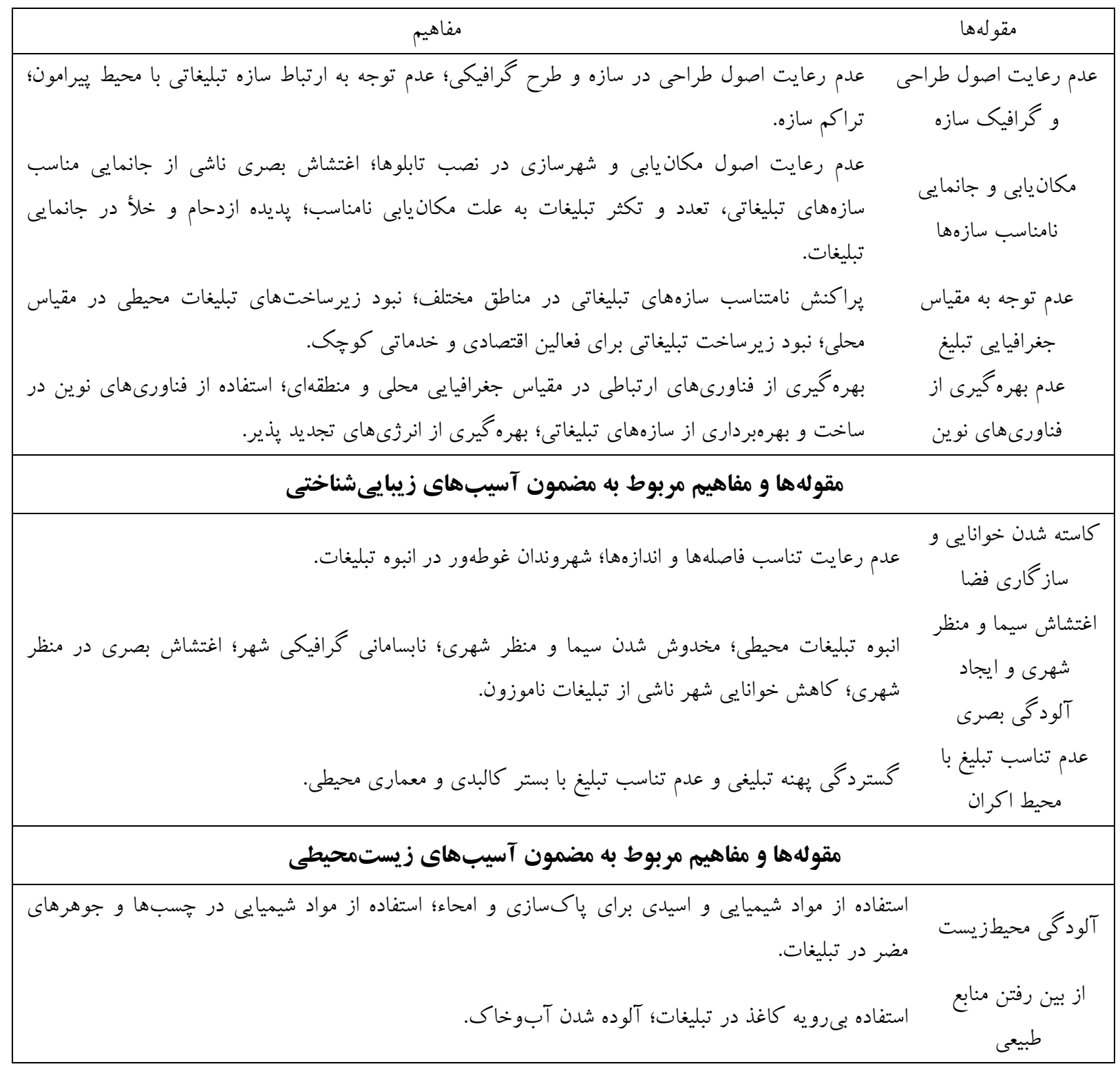


جدول ب- جمعبندى نهايى مضامين

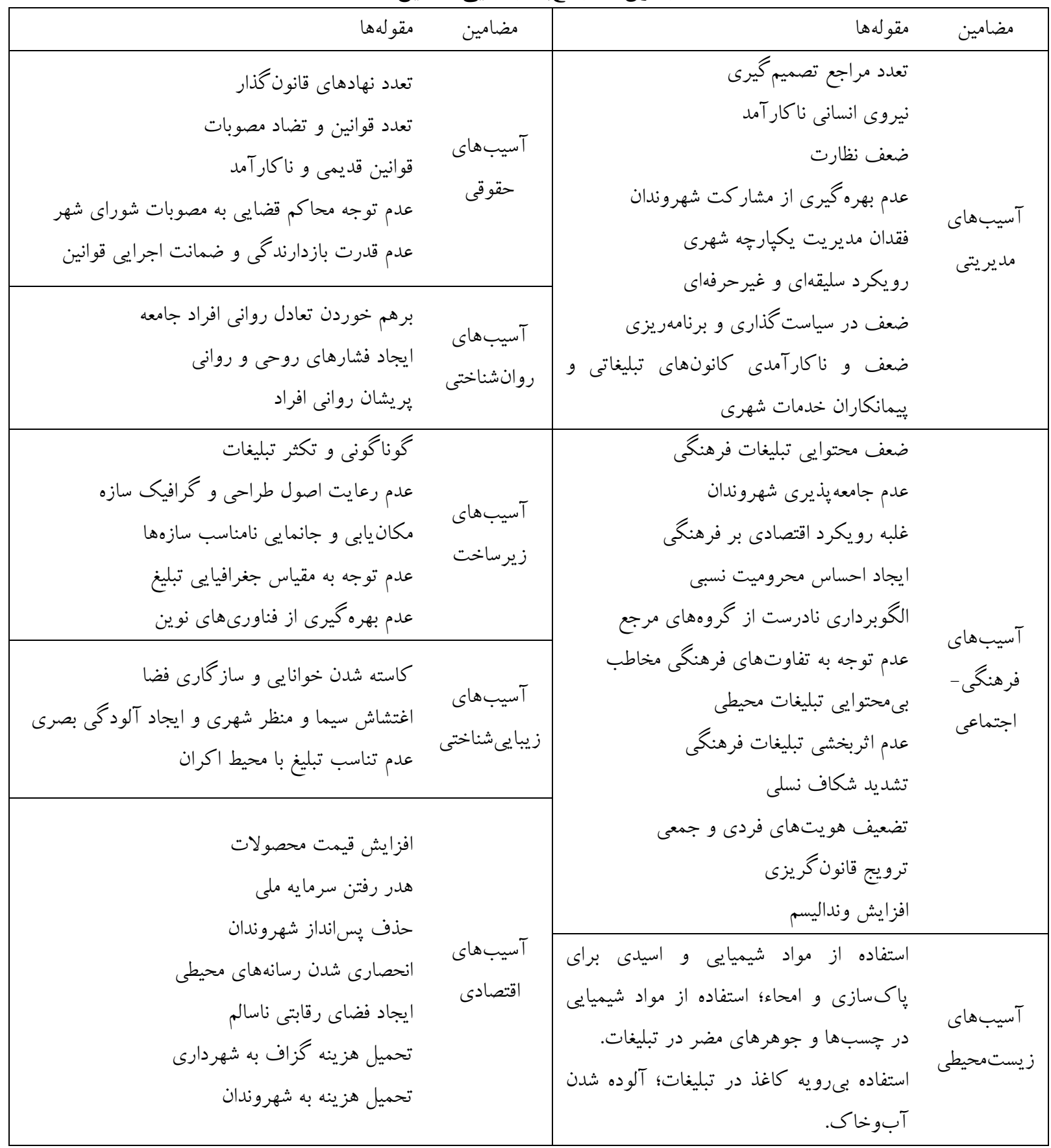

جامعه ايران، جامعهاى در حال كذار است. فر آيند كذار در اثر عواملى ازجمله كُترش و جهانىشدن رسانهها و تبليغات هم

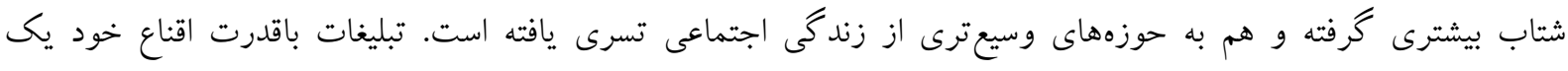

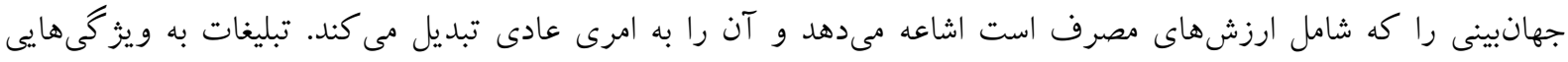

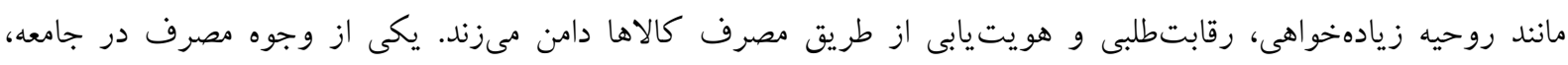

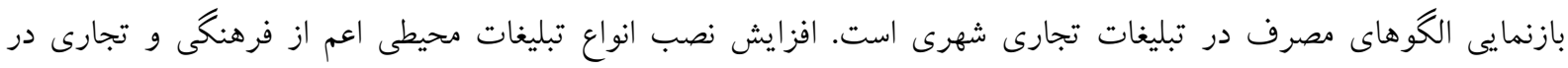

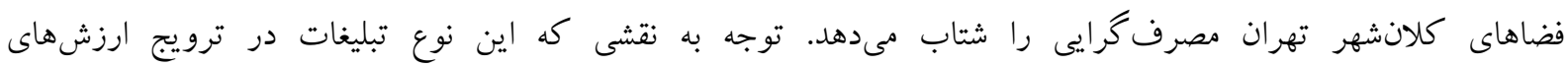

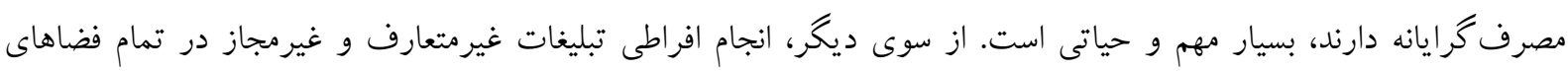

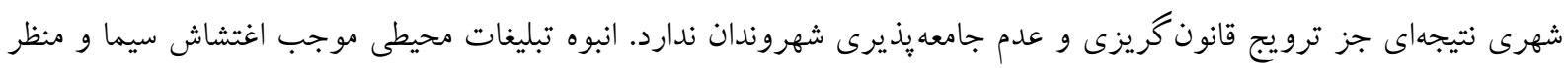


IT/10. شهرى، آلود گى بصرى و كاسته شدن خوانايى و ساز گارى عناصر شهرى شده است كه موجب افزايش فشارهاى روحى بر

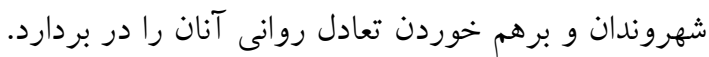

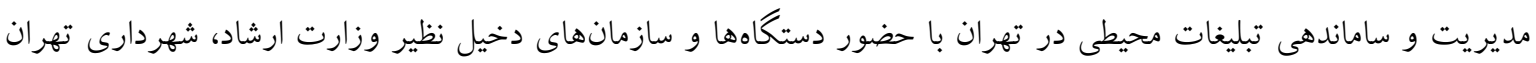

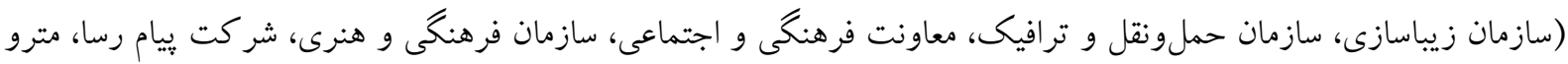

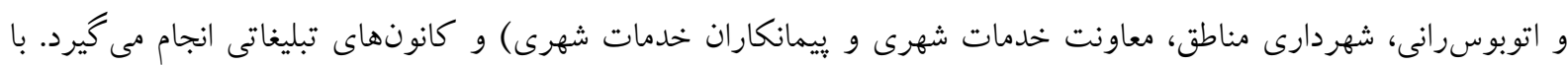

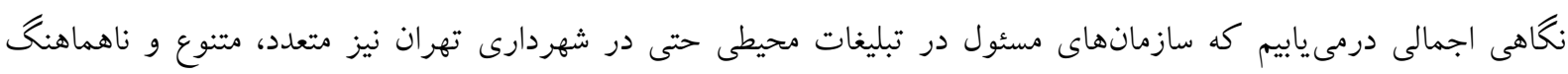

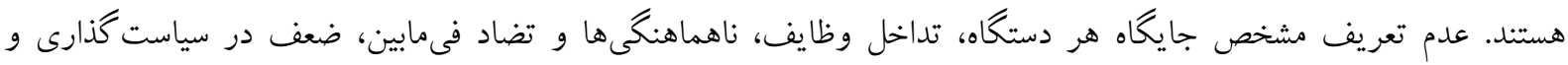

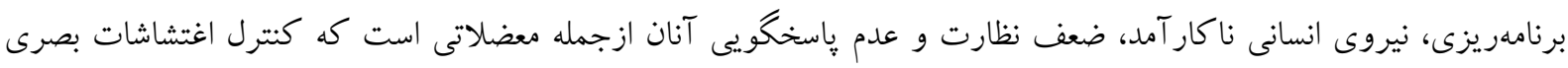

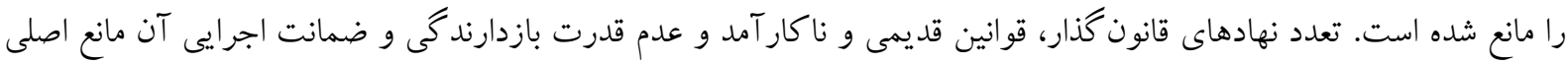

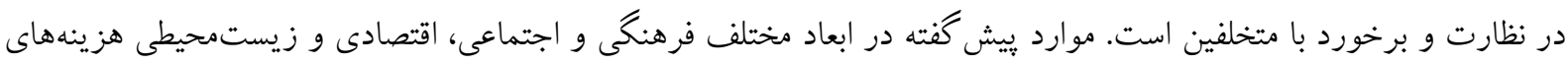
كزافى به مديريت شهرى و شهروندان تحميل كرده است.

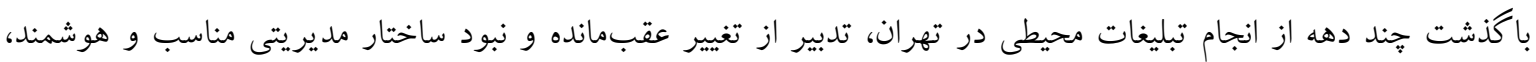

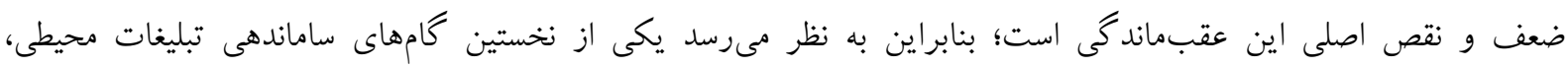

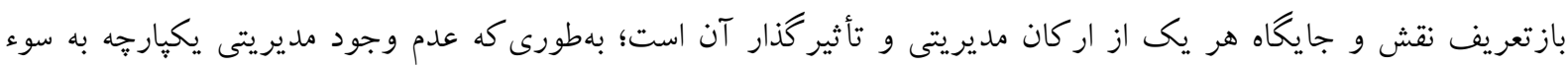

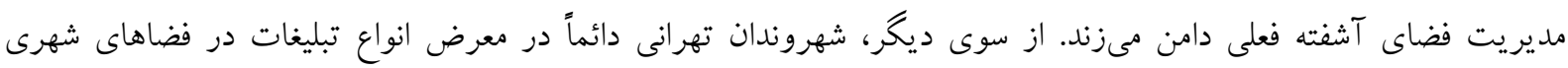

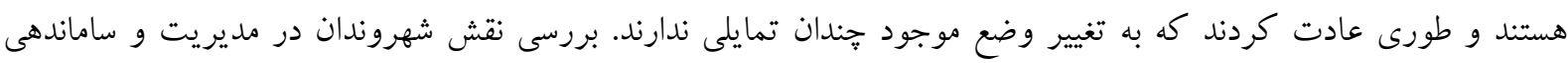

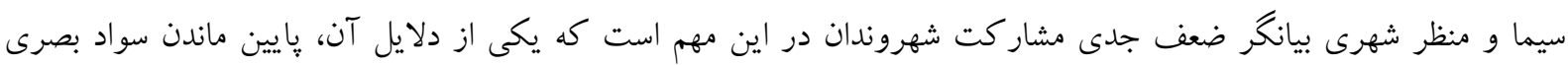

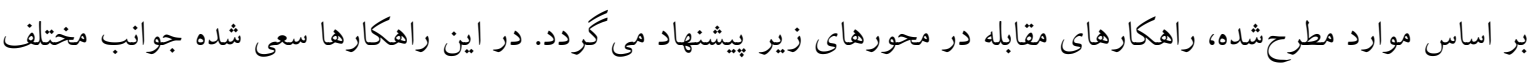

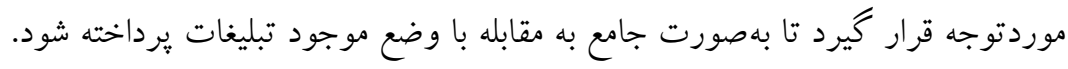

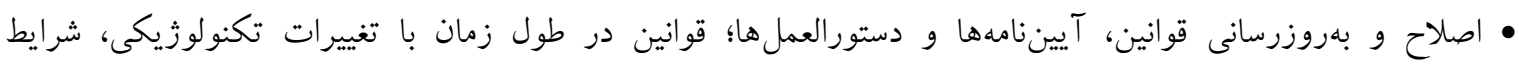

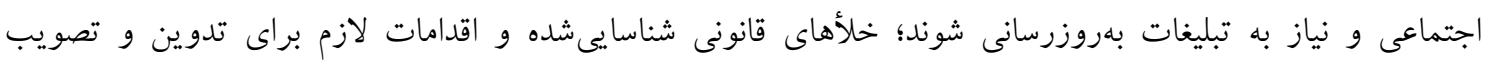

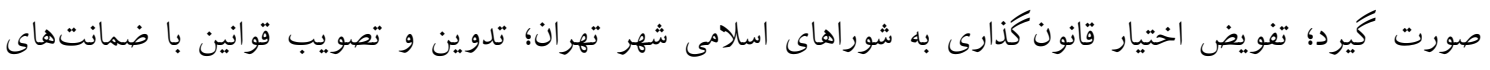

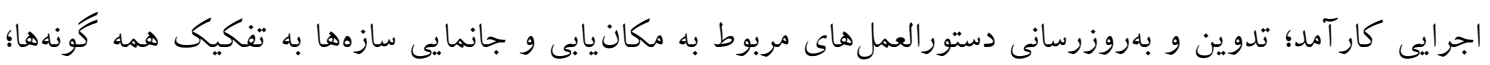

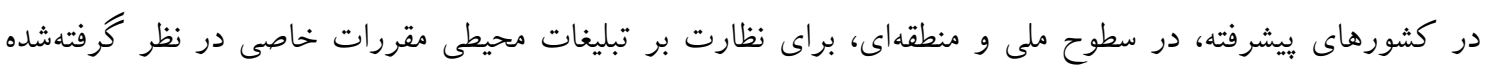
است كه زير نظر مستقيم يك شوراى عالى تصميم گيرى مى كنئد.

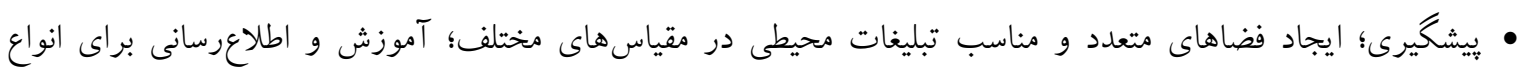
كروههاى اجتماعى. • استفاده از فن آورى هاى اطلاعات؛ دوربين مداربسته؛ نصب اخطاريه؛ استفاده از يوششهاى بازدارنده؛ ايجاد ديوارهاى موقت؛ نقاشى ديوارى و سراميك كارى ديوارها؛ تعامل با سازمانها و نهادهاى مختلف و جلب مشار كت و همكارى آنها؛ عدم واكذارى فضاهاى قانونى تبليغات محيطى به متخلف؛ محروم ساختن متخلفين تبليغات محيطى از خدمات 


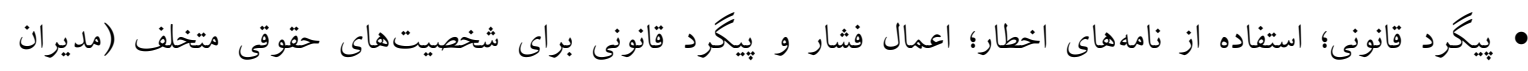
شر كتها)؛ معرفى قانونشكنان به ساكنان از طريق مطبوعات و تبليغات محيطى محلى؛ تشكيل بانكى اطلاعاتى متخلفان

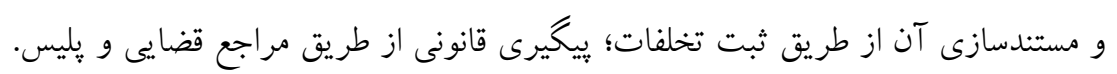

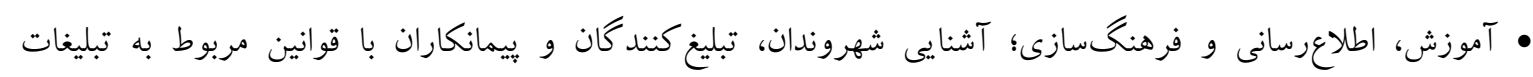

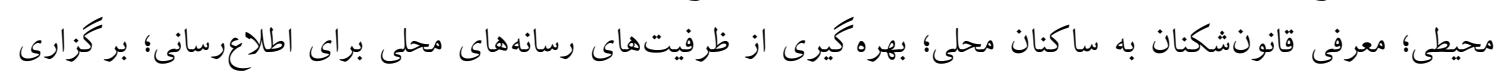

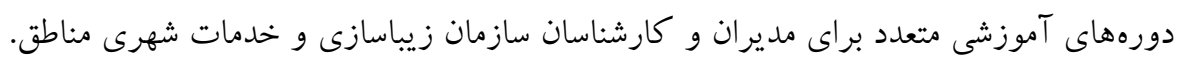

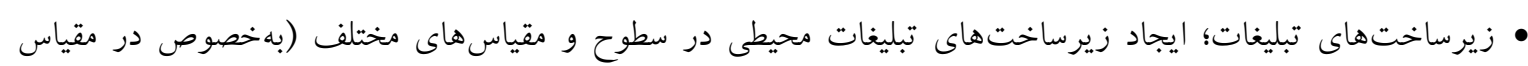

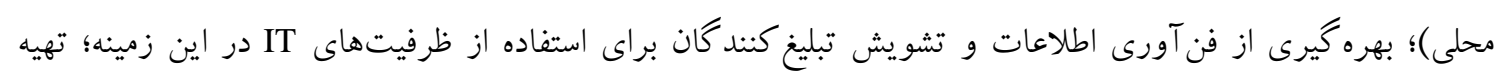

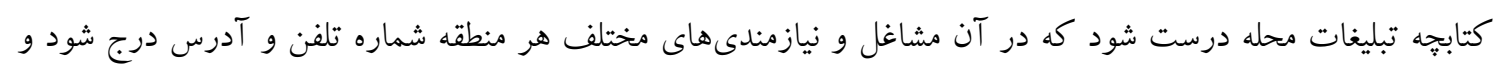

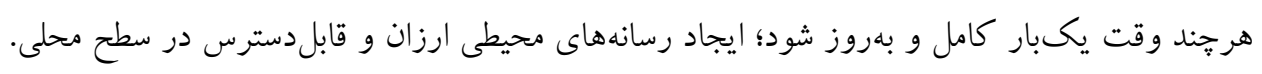

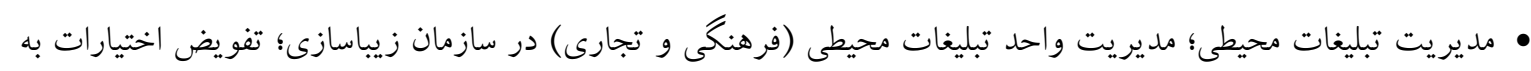

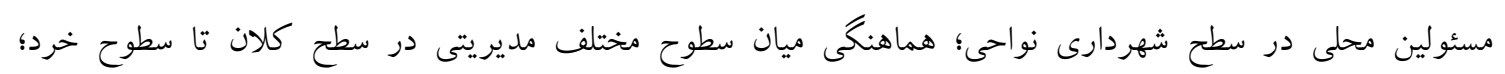

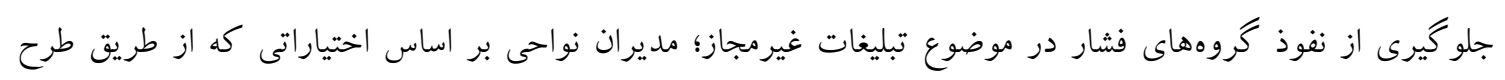

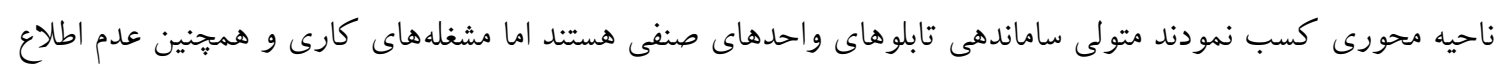

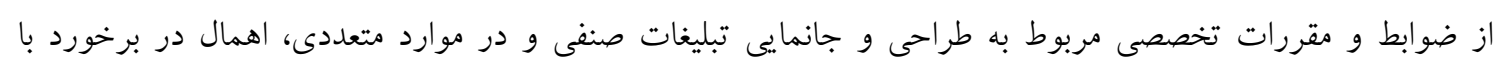

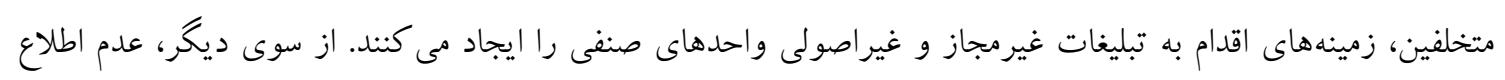

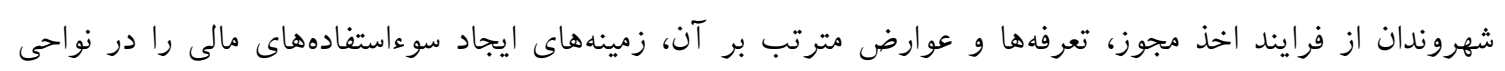
فراهم مى كند.

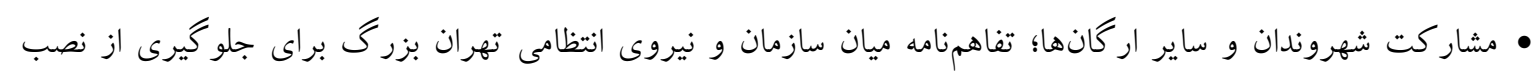

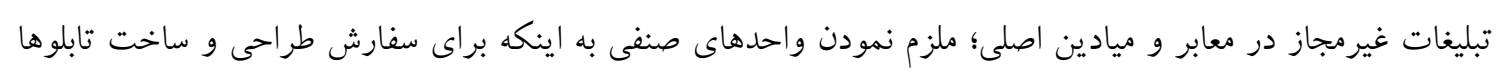

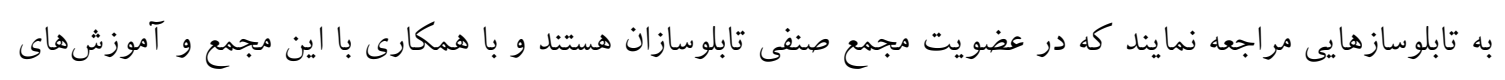

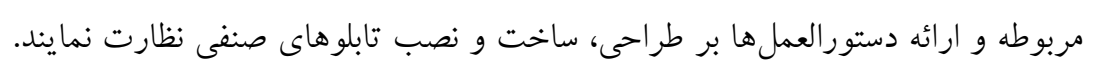

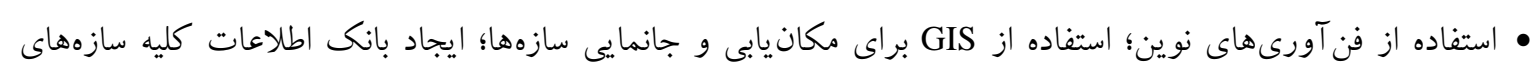

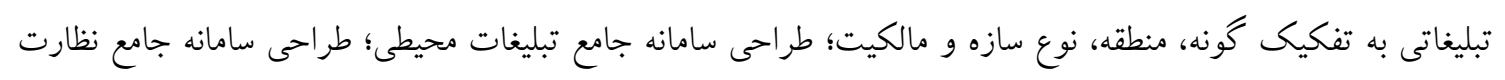

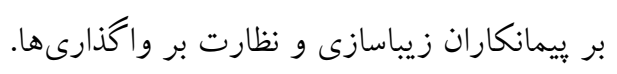

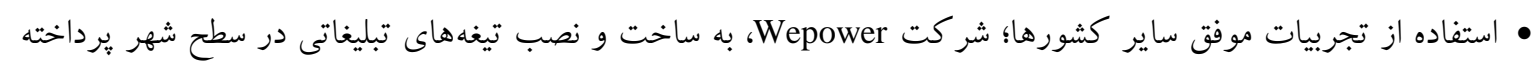

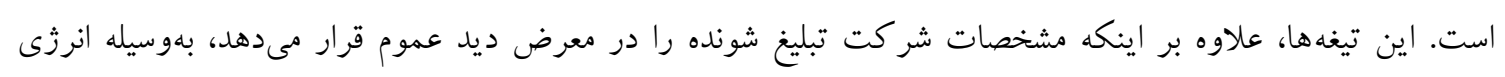

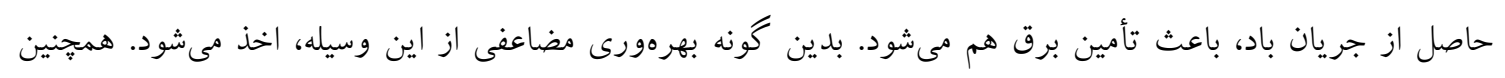

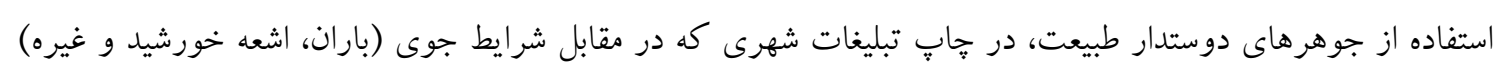

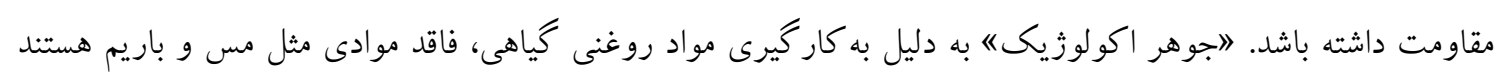

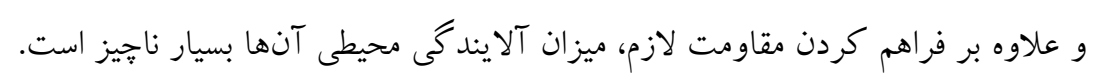

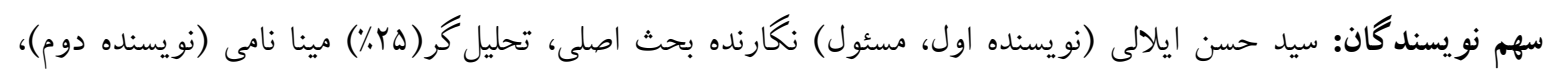

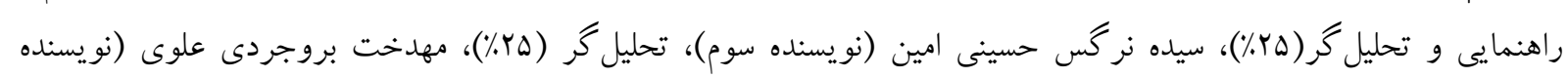
جهارم)، تحليل 


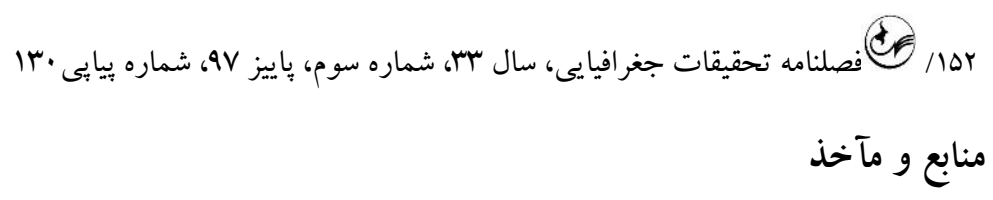

Abbasi, B., Gholipour, A., Delavare, A., \& Jafari, P. (2009). Qualitative research on the effect of commercialization approach on traditional university values. Journal of Science \& Technology Policy, 2(2), 63-76. (Persian)

Abouei Ardakan, M., Labafi, S., Azarpour, S., \& Jalalpur, M. (2014). Identifying the critical factors of strategic thinking success in the viewpoint of managers of cultural organizations of Isfahan. Executive Management Research Journal, 6(11), 13-34. (Persian)

Ahmadi, T. (2010). Environmental advertising engineering. Tehran: Farazandish Sabz. (Persian)

Bashiru, S., \& Bunyaminu, A. (2013). A critical analysis on advertising banks products and services in Ghana. International Journal of Marketing Studies, 5(3), 117. [DOI:10.5539/ijms.v5n3p117]

Bonyanian, H. (1998). A model on the pathology of the Islamic Revolution, pathology of the Islamic Revolution. Tehran: Representation of Supreme Leader in Sharif University of Technology. (Persian)

Braun, V., \& Clarke, V. (2006). Using thematic analysis in psychology. Qualitative research in psychology, 3(2), 77-101.

Chan, K., \& Cheng, B. (2012). Awareness of outdoor advertising in Hong Kong. International Journal of Consumer Research, 1(1), 81-97.

Chervin, N. (2011). Environmental advertising in the context of the theory (M. Jafari, Trans.) Journal of City, Life, Beauty, Promotion of Environmental Advertising. (Persian)

Defleur, M., \& Dennis, E. (2013). Understanding mass communication (S. Moradi, Trans.). Tehran: Faculty of Broadcasting Publishing. (Persian)

Fourie, P. (2008). Media studies: Media history, media and society (2nd ed. Vol. 1). South Africa: Juta Academic.

Ghafouri, S., \& Asghari, A. (2012). Advertising urban morphology in Tehran. Tehran: Dibaei. (Persian)

Ghalenoi, M., Bahramian, A., \& Madani, F. (2011). The role of shop floorboards in changing the urban landscape (case study: Charbagh Abbasi street). Comparative Studies of Art, 1(2), 29-39. (Persian)

Gidens, A. (2017). Ociology (M. Sabouri, Trans.). Tehran: Ney Publishing. (Persian)

Gray, P. S., Williamson, J. B., Karp, D. A., \& Dalphin, J. R. (2007). The research imagination: An introduction to qualitive and quantitative methods (First Ed.). Cambridge, UK: Cambridge University Press.

Hasanrezaei, H. (2016). The broken window theory, and revising some tales and proverbs in farsi literature, cultural community studies. Research Institute of Humanities and Cultural Studies, 7(4), 79-93. (Persian)

Heidari, O., Zebardast, L., \& Asgari Rad, F. (2017). Study and evaluation of environmental promotion in urban spaces (case study: Interventions of the Islamic Revolution Square to the Valiasr Square of Tehran). Journal of Environmental Science and Technology, Online Publication of History May 27th, (Persian)

Hesse-Biber, N., \& Leavy, P. (2003). Approaches to qualitative research. New York: Oxford University Press.

Kelling, G., \& Wilson, J. (2003). Broken windows: The police and neighborhood safety. The Judiciary Law Journal, 43, 179-204. (Persian)

Kim, S., \& Jun, J. (2016). The impact of event advertising on attitudes and visit intentions. Journal of Hospitality and Tourism Management, 29, 1-8. [DOI:10.1016/j.jhtm.2016.04.002]

King, N., \& Horrocks, C. (2010). Interviews in qualitative research. London: Sage.

Kvale, S. (1996). Interviews views: An introduction to quantitative research interviewing. Thousand Oaks , CA: Sage.

Mahdizadeh, S. (2012). Media theories: Common thoughts and critical views. Tehran: Hamshahri. (Persian)

Majidi Ghahroodi, N., \& Abbasi, F. (2012). The role of environmental advertising (inbound buses advertising) on persuading the audience to buy goods in the 14 district of Tehran. Culture of Communication, 2(6), 127-149. (Persian)

Mcquail, D. (2010). Mcquail's mass communication theory. London: Sage publications.

Mohammadian, M., \& Pourhosseini, A. (2012). Environmental advertising; Abandoned advertising capacity in Iran. Tehran: Mehraban Publishing. (Persian)

Mohammadpour, A. (2013). Qualitative research method, anti-method 2: Levels and practical procedures in qualitative methodology. Tehran: Sociologists. (Persian)

Mokhtari Naseri, L., Hassanpour, M., \& Khatayi, S. (2015). The effect of environmental advertising on society culture. Paper presented at the The First National Conference on Environmental Advertising in Iran, Tehran, University of Science and Culture. (Persian)

Moradi, M. (2014). Paradigm shift from quantitative research to qualitative research in humanities. Journal of Research, 24(57), 93-116. [DOI:10.22034/Rahyaft.2014.24.57.537557]. (Persian) 
Nazeri, A., Sobhanifard, Y., \& Ettehad mohkam, S. (2016). Evaluation of effectiveness factors on use of commercial billboard design by Isfahan advertising company. A Bi-Quarterly Journal of Pazhuhesh-e Honar, 6(11), 87-98. (Persian)

Payandeh, H. (2006). A critical reading of commercial ads on Iran's television. Tehran: Roznegar. (Persian)

Postman, N. (2015). Life in sash, dying in happiness (S. Tabatabai, Trans.). Tehran: Newspaper Etelaat. (Persian)

Poulos, N. S., \& Pasch, K. E. (2015). The Outdoor MEDIA DOT: The development and inter-rater reliability of a tool designed to measure food and beverage outlets and outdoor advertising. Health \& place, 34, 135142. [DOI:10.1016/j.healthplace.2015.05.007]

Ritzer, G. (2015). Theories of sociology in contemporary (M. Solathi, Trans.). Tehran: Elmi Publishing. (Persian)

Sajjadi, E. (2011). Advertising management. Tehran: Ramand Publishing. (Persian)

Salehi Amiri, S. (2016). Concepts and Cultural Theories. Tehran: Ghoghnos Publishing. (Persian)

Seidman, I. (2006). Interviewing as qualitative research: A guide for researchers in education and the social sciences. New York, USA: Teachers College Press.

Terkan, R. (2014). Importance of creative advertising and marketing according to university students' perspective. International Review of Management and Marketing, 4(3), 239-246.

Valkenburg, P. M. (2000). Media and youth consumerism. Journal of Adolescent Health, 27(2, Supplement 1), 52-56. [DOI:10.1016/S1054-139X(00)00132-4] 